\title{
Blood biomarkers for mild traumatic brain injury: a selective review of unresolved issues
}

\author{
Daniel B. Hier ${ }^{*}$ (D), Tayo Obafemi-Ajayi², Matthew S. Thimgan³ , Gayla R. Olbricht ${ }^{4}$, Sima Azizi ${ }^{1}$,
} Blaine Allen ${ }^{1}$, Bassam A. Hadi ${ }^{5}$ and Donald C. Wunsch $\|^{1,6}$

\begin{abstract}
Background: The use of blood biomarkers after mild traumatic brain injury (mTBI) has been widely studied. We have identified eight unresolved issues related to the use of five commonly investigated blood biomarkers: neurofilament light chain, ubiquitin carboxy-terminal hydrolase-L1, tau, S100B, and glial acidic fibrillary protein. We conducted a focused literature review of unresolved issues in three areas: mode of entry into and exit from the blood, kinetics of blood biomarkers in the blood, and predictive capacity of the blood biomarkers after mTBI.

Findings: Although a disruption of the blood brain barrier has been demonstrated in mild and severe traumatic brain injury, biomarkers can enter the blood through pathways that do not require a breach in this barrier. A definitive accounting for the pathways that biomarkers follow from the brain to the blood after mTBI has not been performed. Although preliminary investigations of blood biomarkers kinetics after TBI are available, our current knowledge is incomplete and definitive studies are needed. Optimal sampling times for biomarkers after mTBI have not been established. Kinetic models of blood biomarkers can be informative, but more precise estimates of kinetic parameters are needed. Confounding factors for blood biomarker levels have been identified, but corrections for these factors are not routinely made. Little evidence has emerged to date to suggest that blood biomarker levels correlate with clinical measures of $\mathrm{mTBI}$ severity. The significance of elevated biomarker levels thirty or more days following $\mathrm{mTBl}$ is uncertain. Blood biomarkers have shown a modest but not definitive ability to distinguish concussed from non-concussed subjects, to detect sub-concussive hits to the head, and to predict recovery from mTBI. Blood biomarkers have performed best at distinguishing CT scan positive from CT scan negative subjects after mTBI.
\end{abstract}

Keywords: NF-L, UCH-L1, GFAP, Mild traumatic brain injury, Kinetics, S100B, Blood biomarkers, Tau, Concussion, Return to sport, CT scan

\section{Background}

Mild traumatic brain injury (mTBI), also known as concussion, has been defined as a minor head injury with a Glasgow Coma Scale score of 13 to 15. Loss of consciousness and post traumatic amnesia occur variably. The CT scan and MRI may be normal or show minor

\footnotetext{
${ }^{*}$ Correspondence: hierd@mst.edu

'Department of Electrical and Computer Engineering, Missouri University of Science and Technology, Rolla MO 65401, USA

Full list of author information is available at the end of the article
}

abnormalities. A variety of protein macromolecules and smaller molecules detectable in the blood and cerebrospinal fluid have been investigated as biomarkers for mTBI [1-13]. This review focuses on five of the most commonly studied markers for mTBI: glial fibrillary acidic protein (GFAP), neurofilament light chain protein (NF$\mathrm{L})$, ubiquitin C-terminal hydrolase-L1 (UCH-L1), tau, and S100B. Since these five protein biomarkers have been extensively reviewed, we briefly highlight some of their important features as a context for this review. Glial fibrillary acidic protein, a $50 \mathrm{kDa}$ protein, is the primary 
component of intermediate filaments in astrocytes [5]. GFAP monomers homo-polymerize to form the intermediate filament cytoskeleton of astrocytes [14, 15]. GFAP is upregulated during astrogliosis and is likely released from astrocytes after traumatic brain injury [6]. Levels of GFAP are elevated in both the cerebrospinal fluid and blood after TBI $[16,17]$. Neurofilament protein comes in three forms: a $200 \mathrm{kDa}$ heavy chain (NF-H), a $150 \mathrm{kDa}$ medium-chain (NF-M), and a $68 \mathrm{kDa}$ light chain (NF-L). The backbones of $10 \mathrm{~nm}$ diameter neurofilaments in neurons are assembled by the polymerization of neurofilament light chains and the side arms are made from neurofilament medium and heavy chains $[18,19]$. Mature neurofilaments provide a stable framework within the axons of neurons. NF-L protein has a slow turnover in axons with an estimated intracellular half-life of 3 weeks [18, 20]. NF-L levels are increased in both the blood and cerebrospinal fluid after TBI [21]. Ubiquitin C-terminal hydrolase-L1 is a $25 \mathrm{kDa}$ enzyme that is highly expressed in neurons. It is involved in ubiquitination and de-ubiquitination of proteins allocated for catabolism. Blood and cerebrospinal fluid levels of UCH-L1 are elevated after TBI [22].

Tau is a protein involved in the stabilization of microtubules in the axons of neurons in both the central and peripheral nervous system. In the central nervous system, tau has six isoforms (A-F) with molecular weights ranging from $33 \mathrm{kDa}$ to $46 \mathrm{kDa}$ [23]. Tau has been measured after TBI in a variety of forms, including cleaved-tau (tau-C), phosphorylated-tau (tau-P), and total tau (tau-T). Although elevated tau levels indicate neuronal injury, tau is released into the interstitial fluid by healthy neurons [24]. Intracellular turnover of tau is slow, with an estimated half-life of 19-30 days [24]. Tau is elevated in the plasma and cerebrospinal fluid after TBI [25]. S100B (formerly $\mathrm{S} 100-\beta$ ) is a low-molecular weight $10 \mathrm{kDa}$ calciumbinding protein expressed in glia and Schwann cells. Blood levels of S100B may be elevated after trauma without head injury [7]. Immediately after TBI, extracranial sources of S100B may be significant [26]. Elimination of S100B from the blood is rapid with a half-life between 0.5 and $2 \mathrm{hrs}$ [26-28]. After TBI, levels in the cerebrospinal fluid may be up to 100 times higher than serum levels [26].

\section{Selection of issues for focused review}

Despite much investigation of blood biomarkers in the settings of mild, moderate, and severe brain injury, some issues regarding their use remain unresolved [4-12]. McDonald et al. [13] have recently emphasized that known unknowns exist for the use of blood biomarkers for mTBI including the mechanism by which biomarkers gain entry to the blood (via blood brain barrier or glymphatic system), biomarker kinetics including rates of absorption and elimination, and analytic issues (including obtaining, processing, and analyzing blood samples). This review focuses on eight unresolved issues related to the use of blood biomarkers to diagnose and manage mTBI

1. How do biomarkers enter and exit the blood?

2. What are the kinetics of blood biomarkers?

3. What is the optimal sampling time for blood biomarkers?

4. How long do the blood biomarker levels remain elevated?

5. What are the confounding factors for blood biomarker levels?

6. Can blood biomarkers differentiate between subjects with concussions or sub-concussive hits to the head from healthy controls?

7. Can blood biomarkers predict CT scan positivity?

8. Can blood biomarkers predict outcome or severity of $\mathrm{mTBI}$ ?

This list of unresolved issues is selective and is not comprehensive. Most of the literature discussed in this paper stems from the intersection of the searches in Ovid MEDLINE and Epub Ahead of Print (1946 to February 5, 2021) for the keyword traumatic brain injuries $(15,999)$ and the search terms UCH-L1 OR GFAP OR tau proteins OR S100 proteins OR neurofilament proteins $(54,631)$ which yielded 406 articles. We added 202 articles with the search terms glymphatic system OR periarterial drainage. We added 195 articles from ad hoc searches. We reviewed the titles and abstracts of 803 full-text publications to select the 140 articles retained for this review.

\section{Review findings}

How do biomarkers enter and exit the blood after mTBI?

After mTBI, axonal shearing and cellular disruption cause the release of biomarkers from neurons and astrocytes $[1,8]$. NF-L, UCH-L1, and tau are released from neurons; GFAP and S100B are released from astrocytes [8]. These biomarkers are released into the surrounding interstitial fluid. A dose-response relationship for the release of biomarkers has not been established, i.e. there no proven linear or non-linear relationship between the amount of biomarker released into the interstitial fluid and the force of the impact to the head. Bui et al. [29] examined the modality of blood biomarker levels after mTBI in a dataset of concussed athletes from the Concussion Assessment, Research, and Education Consortium Study (CARE) study [30, 31]. (Data is available via the Federal Interagency Traumatic Brain Injury Research (FITBIR) [32] repository to approved investigators.). Based on a test for modality, we found that biomarker levels after concussion were multi-modal rather that than uni-modal [29]. When subjects were clustered by biomarker trajectory after mTBI, some clusters showed a robust rise in biomarker levels while others showed a modest or minimal rise in biomarker levels [29] (Fig. 1). 


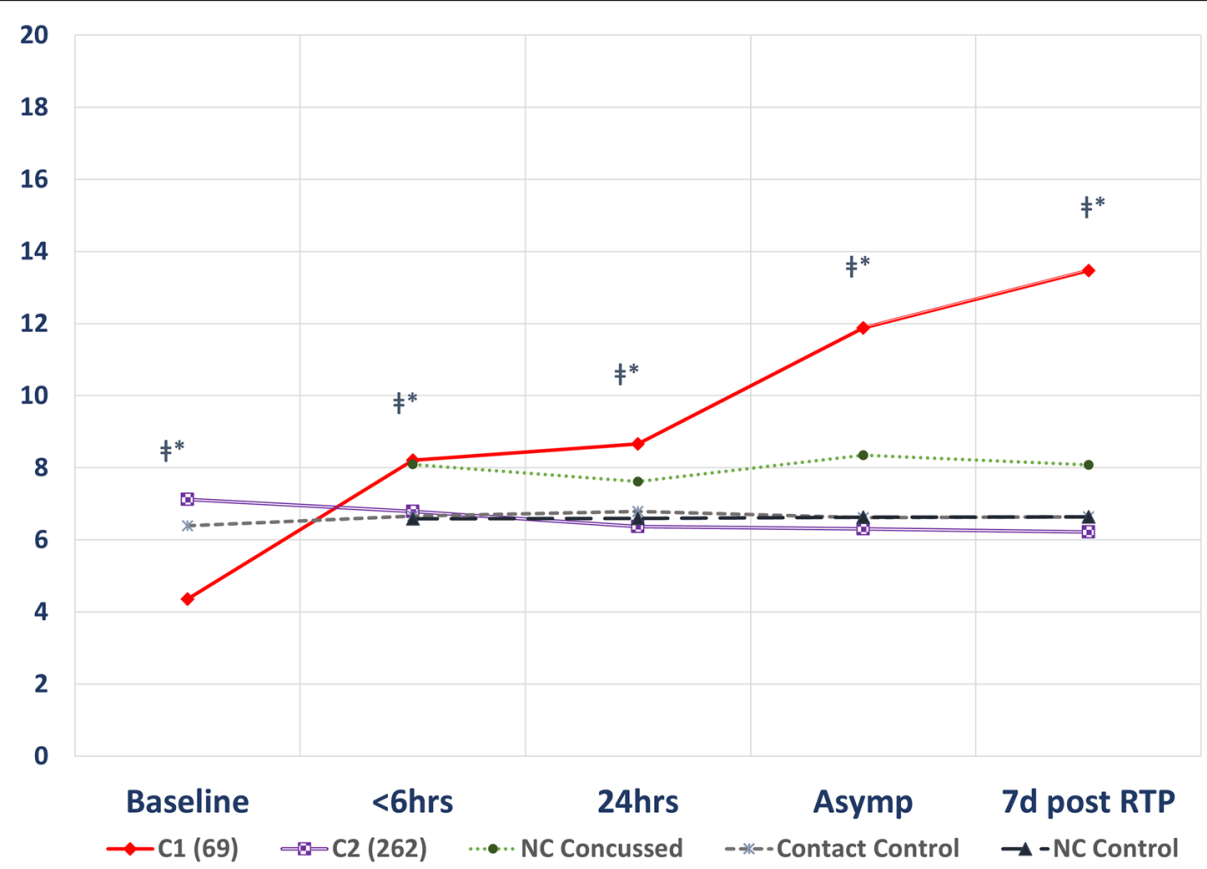

Fig. 1 Cluster trajectories for NF-L biomarker for concussed contact sport subjects formed two clusters C1 and C2. C1 (red line) showed a robust rise in NF-L after concussion whereas C2 (purple line) showed a modest elevation in NF-L not much different from the non-contact sport concussed, contact sport controls, and not-contact sport controls. C1 and C2 differed at all time points $(p<0.05)$. Reproduced from [29] with permission. Original data from CARE study [30]

With a volume of approximately $1200 \mathrm{ml}$, the human brain is tightly packed with cellular elements (neurons, astrocytes, oligodendrocytes and their myelin, and microglia). About $20 \%$ of the brain is extracellular space [33]; filled with an extracellular matrix and approximately $120 \mathrm{ml}$ of interstitial fluid. The interstitial fluid brings nutrients to the neurons and glia of the brain and removes waste products. Proteins move through the interstitial fluid by diffusion or more rapidly by convection [33-35]. The extracellular space is highly confined with narrow passages that are 38-64 nm diameter [33]. Given the large size of some protein biomarkers (Table 1), these tight passages can slow the diffusion of biomarkers. Movement in these tight passages is by hindered diffusion and larger molecules are slowed more than smaller molecules [33, 37]

After mTBI, biomarkers can potential diffuse through the extracellular space of the brain to penetrating blood vessels and enter the blood if the blood brain barrier is disrupted. Disruption of the blood brain barrier occurs with moderate or severe brain injury in about $40 \%$ of the cases $[38,39]$. It is less certain whether disruption of the blood brain barrier occurs routinely with mild traumatic brain injury [13]. Using meningeal enhancement on MRI as a surrogate for disruption of the blood brain barrier, it has been suggested that transient disruption of the blood brain occurs in about $50 \%$ of the cases of mTBI [40]. It is possible that some biomarkers reach the blood by diffusing to the vessel walls in the brain and crossing the blood brain barrier directly [13]. Nonetheless, given that biomarkers can be detected in the blood of normal individuals with intact blood brain barriers and that many subjects with mTBI do not have a disruption of the blood brain barrier, it is likely that other routes account for some entry of biomarker into the blood after mTBI.

After TBI, levels of biomarkers in the cerebrospinal fluid rise rapidly, suggesting that these biomarkers have easy access to the cerebrospinal fluid from the interstitial fluid. Biomarkers can reach the cerebrospinal fluid by transependymal flow into the ventricles or trans-pial flow into the subarachnoid space [35]. Once in the cerebrospinal fluid, biomarkers circulate by convection or diffusion. The traditional model of the cerebrospinal fluid circulation $[41,42]$ involves the production of cerebrospinal fluid by the choroid plexus, passage through the aqueduct to the fourth ventricle and then flow outward to the convexities of the brain and to the lumbar subarachnoid space [43].

The cerebrospinal fluid volume $(150 \mathrm{ml})$ turns over four times per day [43]. Some cerebrospinal fluid is absorbed into the blood at the arachnoid granulations along the superior sagittal sinus. It is uncertain to what extent protein biomarkers can traverse the narrow passages of the arachnoid granulations to leave the cerebrospinal fluid and enter the blood. Most cerebrospinal fluid exits 
Table 1 Some Properties of Proteins Investigated as Biomarkers for mTBI

\begin{tabular}{llllll}
\hline Biomarker & MW $\boldsymbol{\dagger}$ & Residuest & Role & Localization & Cell \\
\hline S100B & 10.7 & 92 & regulatory & cytoplasm & astrocyte \\
UCH-L1 & 24.8 & 223 & enzymatic & cytoplasm & neuron \\
tau isoform A§ & 32.9 & 316 & structural & axon & neuron \\
tau isoform F§ & 45.8 & 441 & structural & axon & neuron \\
GFAP & 49.9 & 543 & structural & cytoplasm & astrocyte \\
NF-L & 61.5 & 304 & structural & axon & neuron \\
\hline
\end{tabular}

${ }^{5}$ Human CNS tau has 6 isoforms A-F [23].

${ }^{\dagger}$ Molecular weight (MW) in kDa, Residues is the number of amino acids [36]

the cerebrospinal fluid compartment via lymphatic channels [44] at the cribriform plate (olfactory nerve), along other cranial nerve roots and along spinal roots. Radioactively labeled biomarker injected into the lateral ventricles appears in the lymph nodes within 6-8 hrs [44, 45], supporting the importance of these lymphatic routes for the absorption of cerebrospinal fluid and clearance of biomarkers from the cerebrospinal fluid.

It has been recognized for more than 25 years that radioactively labeled albumin injected into the interstitial fluid of the brain can be recovered from cervical lymph nodes draining the head [44]. Since albumin is larger in size than the protein biomarkers for TBI, it is likely that biomarkers released into the interstitial fluid have access to the blood through the lymphatic system. Two competing hypotheses have emerged as to the route of proteins from the interstitial fluid of the brain to the lymphatic system. One group has proposed that proteins and other waste products reach the lymph system through an intramural peri-arterial drainage system [46-50]. This model emphasizes intramural periarterial routes for drainage of protein molecules from the interstitial fluid. A second group [34, 51-57] has proposed a glymphatic system for removal of waste products from the interstitial fluid and their drainage into the lymphatic system. In their model, a convective flow of fluid through the interstitial space between small arteries and veins fosters drainage of waste and proteins into a para-venous space to the lymphatic system. The exact mechanism and precise anatomy by which biomarkers exit the interstitial fluid and drain into the lymph system and back to the blood remains unsettled $[58,59]$. The relative contributions to blood biomarkers from biomarker transiting directly across the blood brain barrier versus transiting to the blood via the lymphatics is also unsettled [13].

Once in the blood, biomarkers must have a mode of exit. Little is known with certainty about the mode of elimination of biomarkers from the blood. Elimination could occur by redistribution to other compartments, renal excretion, hepatic metabolism, or intravascular proteolysis [13]. Dadas et al. ([60-62] have suggested that elimination of biomarkers after TBI is likely renal and that the rate of elimination is inversely proportional to biomarker molecular weight, with smaller biomarkers eliminated more rapidly than larger ones (e.g. S100B is eliminated more quickly than GFAP). An inverse relationship between renal elimination and molecular weight up to molecules as large as $70 \mathrm{kDa}$ is known [63].

\section{What are the kinetics of blood biomarkers after mTBI?}

When the blood levels of biomarkers are sampled repeatedly after a mTBI, time-concentration curves can be created [64]. The descriptive kinetic parameters time to maximum concentration $\left(T_{\max }\right)$, maximum concentration $\left(C_{\text {max }}\right)$, and half-life $\left(t_{\frac{1}{2}}\right)$ are useful for describing these curves (Fig. 2). A limited number of formal kinetic studies of blood biomarkers after TBI are available [22, 60, 62, $65,66]$. Published time-concentration curves allow estimates of $T_{\text {max }}$ and half-life for the commonly investigated blood biomarkers (Table 2) [1, 9, 11, 12, 17, 65]. Estimates of $T_{\max }$ and half-life are notably uncertain for NF-L due to a paucity of kinetic studies at longer time intervals after mTBI (Table 2). Azizi et al. [74] have modeled the blood levels of biomarkers after mTBI as a one-compartment pharmacokinetic model. In a one-compartment pharmacokinetic model, two first-order rate constants $k_{a}$ (the absorption rate constant) and $k_{e}$ (the elimination rate constant) determine the blood biomarker level at any time $t$ after a mTBI (Eq. 3). Based on published values of $T_{\max }$ and half-life, Azizi et al. estimated $k_{a}$ and $k_{e}$ using Eqs. 1 and 2 [74]. Estimates for $k_{a}$ and $k_{e}$ are shown in Table 2. Kinetic modeling allows an estimate of $C_{p}$ (the biomarker blood level at time $t$ ) if estimates are available for amount of biomarker released $\left(D_{0}\right)$, the fractional absorption rate $(F)$, and the volume of distribution $\left(V_{d}\right)$ as illustrated in Fig. 3. (For details of the model see [74]).

$$
\begin{aligned}
& t_{\frac{1}{2}}=\frac{0.693}{k_{e}} \\
& T_{\max }=\frac{\ln \left(\frac{k_{a}}{k_{e}}\right)}{k_{a}-k_{e}}
\end{aligned}
$$




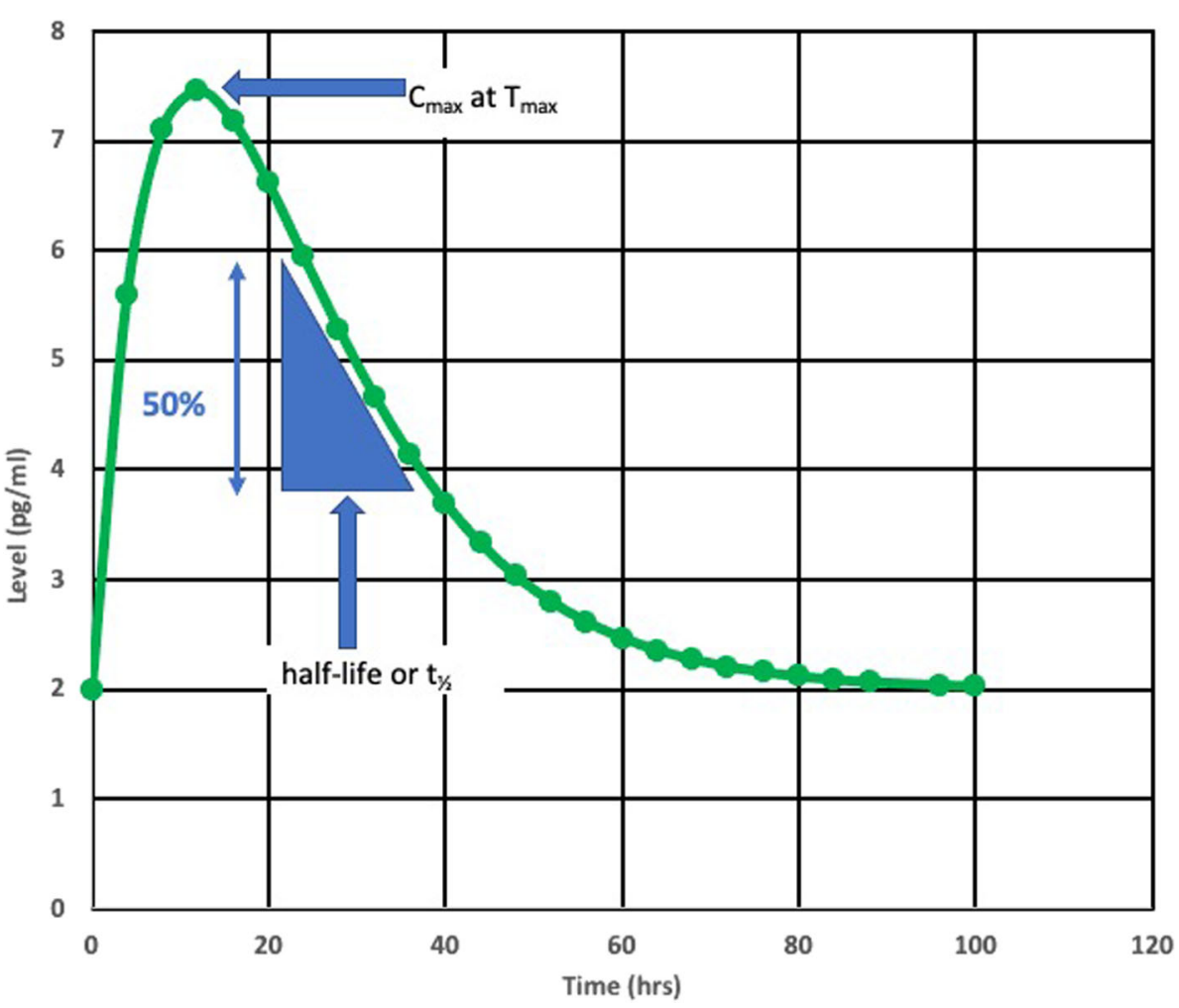

Fig. $2 T_{\max }$ is the time at which the biomarker is at its highest level. The half-life is the time needed for the biomarker level to drop by $50 \%$ during the elimination phase. Accurate estimates of half-life can only be made after the absorption phase is complete. With delayed or continuing absorption of biomarker after mTBI estimates of half-life are difficult

$$
C_{p}=\frac{F * D_{0} * k_{a}}{V_{d} *\left(k_{a}-k_{e}\right)} *\left(e^{-k_{e} t}-e^{-k_{a} t}\right)
$$

Azizi et al. [74] have suggested that the amount of biomarker released at impact $\left(D_{0}\right)$ could serve as a more reliable marker for TBI severity than an isolated blood biomarker level $\left(C_{p}\right)$ at a random time $t$. McDonald et al. [13] have emphasized that whether biomarker is released all-at-once at impact or is released in a delayed or continuing manner after mTBI is another known unknown. The delayed release of biomarker can be modeled in a one-compartment kinetic model by increasing $T_{\max }$ and decreasing the absorption rate constant $\left(k_{a}\right)$ while keeping the amount of biomarker released constant $\left(D_{0}\right)$ [74]. Furthermore, differing kinetic curves for each biomarker (Fig. 3) have implications for selecting the preferred sampling time for each biomarker.

What is the optimal timing for blood biomarker sampling? For some neurological diseases such as fronto-temporal dementia, Alzheimer disease, and multiple sclerosis, blood sample timing for biomarkers is unlikely to be

Table 2 Kinetic parameters of commonly investigated biomarkers for mTBI

\begin{tabular}{|c|c|c|c|c|c|c|c|}
\hline Biomarker & $\begin{array}{l}\text { Normal Plasma } \\
\text { level (pg/ml) }\end{array}$ & $\begin{array}{l}\text { Normal CSF } \\
\text { level }(\mathrm{pg} / \mathrm{ml})\end{array}$ & $\begin{array}{l}\text { Half-life } \\
\text { hrs* }\end{array}$ & $\begin{array}{l}T_{\max } \\
\mathrm{hrs} *\end{array}$ & $k_{a} \ddagger$ & $k_{e} \ddagger$ & References \\
\hline GFAP & $60-70$ & 2100 & 36 & 24 & 0.080 & 0.019 & {$[9,11,12,17,65]$} \\
\hline NF-L & $6-20$ & $400-1100$ & $500 ? ?$ & $100-300 ? ?$ & 0.009 & 0.001 & {$[8,12,67,68]$} \\
\hline $\mathrm{S} 100 \mathrm{~B}$ & $50-60$ & 1800 & $1.5 \dagger$ & 2 & 0.500 & 0.462 & {$[9,11,27,28,65,69,70]$} \\
\hline tau & $1-5$ & 270 & 10 & 8 & 0.070 & 0.069 & {$[8,11,71,72]$} \\
\hline UCH-L1 & $8-10$ & 4500 & 8 & 8 & 0.090 & 0.086 & {$[9,11,17,22,65,73]$} \\
\hline
\end{tabular}

*Values for half-life and $T_{\text {max }}$ are mid-range of reported estimates

${ }^{\dagger} \mathrm{S} 100 \mathrm{~B}$ undergoes rapid redistribution to other compartments before renal elimination

??Estimates are uncertain

‡Estimates for the absorption constant $\left(k_{a}\right)$ and elimination constant $\left(k_{e}\right)$ compartment pharmacokinetic model with first order kinetics from [74]. 


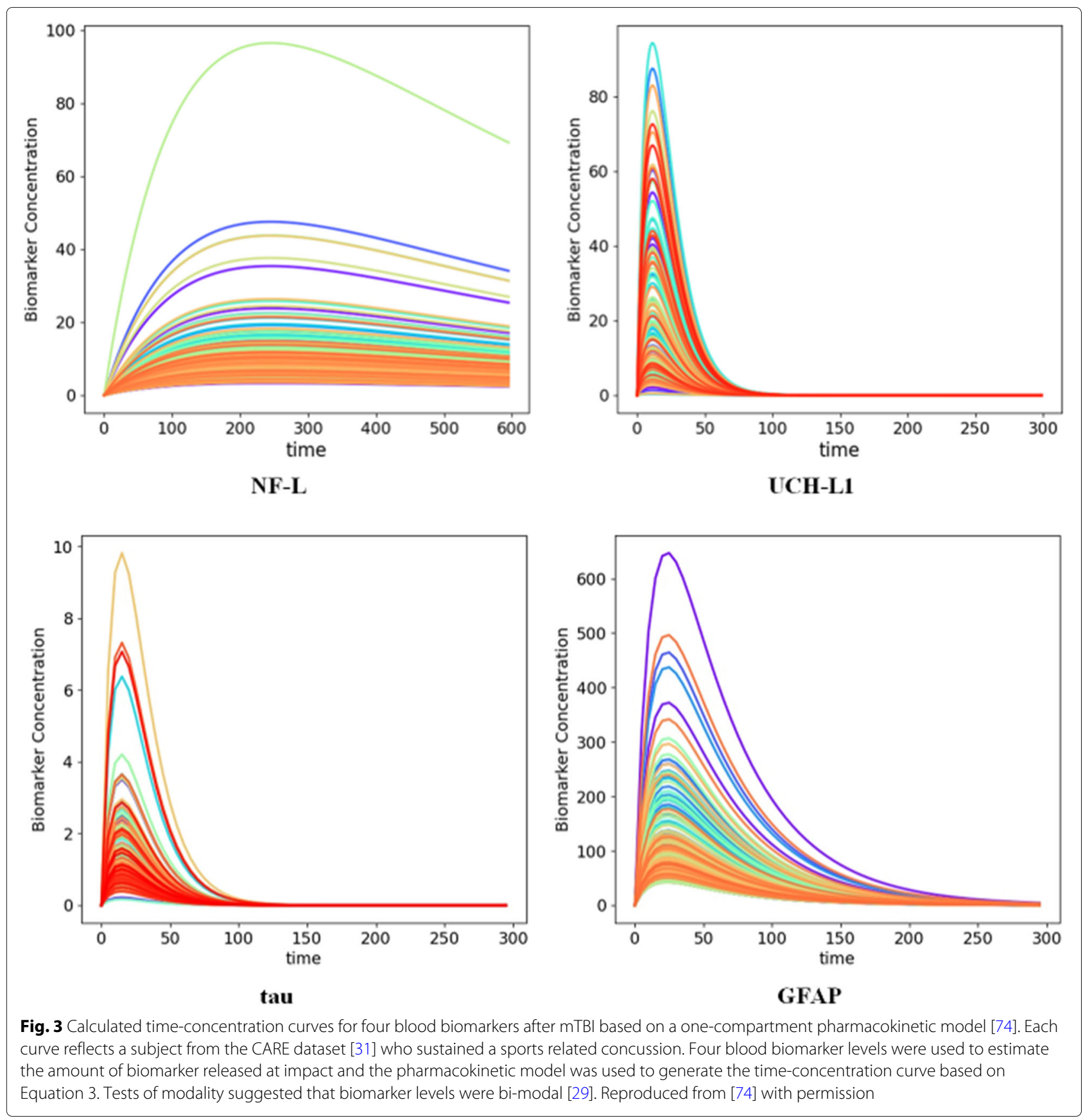

critical [75-77]. With mTBI, like stroke [78], the timing of sampling is important. If blood biomarkers are sampled too early or too late compared to the $T_{\max }$, important elevations may be missed. Based on their approximate $T_{\max }$ (Table 2), it is predicted that $\mathrm{S} 100 \mathrm{~B}$ is best sampled between 0-4 hrs, UCH-L1 and tau between 4-12 hrs, GFAP between 12-36 hrs, and NF-L between 100-300 hrs. Estimates for the $T_{\max }$ of NF-L are not reliable and the actual value of the $T_{\max }$ could be much longer $[12,68]$. Bogoslovsky et al. [10] have emphasized "intended context of use" for blood biomarkers and comment that blood sample times often depend upon the clinical setting (playing field, ED, hospital ward, or rehabilitation center) or the intended use (diagnosis of concussion, decisions around return to sport, or decisions around CT scanning).

Empirical studies are needed to confirm the best sampling times for blood biomarkers after mTBI depending on the intended context of use. In general, the best test performance, as measured by AUROC (area under the receiver operator curve), for S100B, UCH-L1, and tau occurs with early sampling times of 0-6 hrs (Table 3). Note that with the comparison of AUROCs across studies, 
Table 3 Performance at different sampling times for studies with multiple sampling intervals (Area under receiver operator curve) $\dagger$

\begin{tabular}{|c|c|c|c|c|c|c|c|c|c|}
\hline Biomarker & Study & Year & Use & $0-1$ & $0-6$ & $6-24$ & $24-48$ & $48-144$ & $>144$ \\
\hline & Asken [79] & 2018 & concussion & & 0.63 & 0.71 & & & \\
\hline & McCrea [31] & 2020 & concussion & & 0.68 & & 0.57 & & \\
\hline & Meier [80] & 2017 & concussion & & 0.53 & & 0.56 & & \\
\hline & Papa [17] & 2019 & concussion & 0.76 & 0.76 & 0.8 & 0.87 & 0.89 & \\
\hline \multirow[t]{7}{*}{ GFAP } & Posti [81] & 2017 & concussion & & & 0.63 & 0.37 & & \\
\hline & Yue [82] & 2019 & CT-/MRI+ & & 0.72 & 0.85 & & & \\
\hline & Welch [65] & 2017 & $\mathrm{CT}+/ \mathrm{CT}-$ & & 0.84 & 0.94 & & & \\
\hline & McDonald [68] & 2021 & concussion & & & & 0.60 & 0.52 & 0.54 \\
\hline & Giza [83] & 2021 & concussion & & 0.75 & & 0.63 & & \\
\hline & McCrea [31] & 2020 & concussion & & 0.56 & & 0.49 & & \\
\hline & Shahim [84] & 2017 & PCS & & 0.82 & & 0.73 & 0.83 & 0.66 \\
\hline \multirow[t]{5}{*}{$N F-L$} & Shahim [72] & 2018 & RTS & & 0.82 & & 0.72 & 0.73 & 0.73 \\
\hline & McDonald [68] & 2021 & concussion & & & & 0.73 & 0.85 & 0.79 \\
\hline & Giza [83] & 2021 & concussion & & 0.75 & & 0.63 & & \\
\hline & Asken [79] & 2018 & concussion & & 0.75 & 0.69 & & & \\
\hline & Meier [80] & 2017 & concussion & & 0.72 & & 0.58 & & \\
\hline \multirow[t]{6}{*}{ S100B } & Welch [65] & 2017 & $\mathrm{CT}+/ \mathrm{CT}-$ & & 0.78 & 0.75 & & & \\
\hline & Shahim [85] & 2014 & PCS & & 0.68 & & & 0.55 & \\
\hline & Rogatzki [86] & 2021 & concussion & 0.48 & 0.24 & & & & \\
\hline & Asken [79] & 2018 & concussion & & 0.74 & 0.62 & & & \\
\hline & McCrea [31] & 2020 & concussion & & 0.55 & & 0.31 & & \\
\hline & Shahim [85] & 2014 & PCS & & 0.90 & & & 0.76 & \\
\hline \multirow[t]{7}{*}{ tau- $\mathrm{T}$} & Gill [87] & 2017 & RTS & & 0.80 & & & 0.74 & \\
\hline & Shahim [72] & 2018 & RTS & & 0.67 & & 0.57 & 0.52 & \\
\hline & McDonald [68] & 2021 & concussion & & & & 0.51 & 0.55 & 0.72 \\
\hline & Giza [83] & 2021 & concussion & & 0.50 & & 0.46 & & \\
\hline & Asken [79] & 2018 & concussion & & 0.62 & 0.60 & & & \\
\hline & McCrea [31] & 2020 & concussion & & 0.66 & & & & 0.51 \\
\hline & Meier [80] & 2017 & concussion & & 0.74 & & & & 0.55 \\
\hline \multirow[t]{4}{*}{ UCH-L1 } & Papa [17] & 2019 & concussion & 0.65 & 0.65 & 0.77 & 0.74 & 0.50 & \\
\hline & Posti [81] & 2017 & concussion & & 0.52 & 0.46 & & & \\
\hline & McDonald [68] & 2021 & concussion & & & & 0.61 & 0.56 & 0.57 \\
\hline & Giza [83] & 2021 & concussion & & 0.73 & & 0.62 & & \\
\hline
\end{tabular}

*Use: concussion versus controls, mTBI with CT+ versus CT-, delayed return to sport versus no delay, CT- and MRI+ versus CT- and MRI-, post-concussion syndrome versus no post-concussion syndrome.

${ }^{\dagger}$ Time intervals are in hours and are approximate across studies.

Bolded AUROC is the highest row value.

Values are rounded to 2 decimals. No tests of significance were applied.

there are no absolute standards for using the AUROC to evaluate the predictive capacity of a diagnostic test. An AUROC of 0.80 or greater generally suggests that the test is clinically useful [88]. Unlike specificity and sensitivity, AUROC provides a measure of test power that does not depend upon selecting a specific cutpoint [88]. Few studies have examined whether it is possible to sample blood too early after a mTBI. Even rapidly absorbed biomarkers, such as $\mathrm{S100B}$, take a measurable amount of time to be released from injured neural elements, traverse the interstitial fluid, and cross the blood brain barrier or enter drainage pathways to the blood. On the other hand, the fall-off in levels with later sampling times is likely more pronounced for S100B than with UCH-L1 or tau. Due to 
its rapid clearance from the blood, sampling times after 6 hrs are likely to miss important elevations of S100B after mTBI. With the longer half-life of NF-L, a later sampling time can yield a good AUROC. It is unclear if there is a penalty for sampling NF-L too early after a mTBI (Table 3). GFAP, which has a longer half-life than UCH-L1, S100B, or tau, may be better sampled later than the 0-6 hr time frame. For example, Welch et al. [65] found that GFAP as a predictor of CT positivity performed better when drawn at 12-18 hrs instead of 0-6 hrs. More investigation is needed to set the optimal sampling time for each blood biomarker for mTBI.

\section{What are the confounding factors for blood biomarker levels after $\mathrm{mTBI}$ ?}

One confounding factor for biomarker blood levels is total blood volume (TBV). Individuals with higher blood volumes have lower blood biomarker levels. Manouchehrinia et al. [89] studied NF-L levels in 2,586 multiple sclerosis patients and 662 controls. Mean NF-L levels were 7.52 $\mathrm{pg} / \mathrm{ml}$ in the controls and $11.68 \mathrm{pg} / \mathrm{ml}$ in the multiple sclerosis cases. Plasma NF-L levels dropped by $-0.15 \mathrm{pg} / \mathrm{ml}$ for each liter of TBV in controls and $-0.17 \mathrm{pg} / \mathrm{ml}$ per liter of TBV in multiple sclerosis patients.

Another confounding factor is renal function. Since some elimination of blood biomarker is likely renal, impaired renal function can lengthen biomarker half-life in the blood and elevate biomarker blood levels. Akamine et al. [90] investigated the relationships between blood NF-L levels and renal function in 43 healthy adults and 188 patients with diabetes mellitus. Blood neurofilament levels correlated significantly with creatinine levels in healthy controls $(\mathrm{r}=+0.50)$ and diabetic subjects $(\mathrm{r}=+0.56)$.

Endogenous levels of plasma neurofilament protein, tau, and GFAP are known to rise with age [91-93]. In the TRACK-TBI study, Gardner et al. [94] found that the ability of GFAP to discriminate between CT+ and CTsubjects was less in the older age group (AUROC=0.73) than the middle age $(\mathrm{AUROC}=0.92)$ or young age group (AUROC $=0.93$ ). This age-related effect was not noted with tau. Ward et al. [95] retrospectively examined sensitivity and specificity of the Banyan Brain Trauma Indicator (a tandem GFAP and UCH-L1 assay). They found that while sensitivity was $100 \%$ in the $\geq 65$ and $<65$ age groups, specificity dropped from 0.44 to 0.13 in the older age group. They attributed this drop in specificity to higher levels of GFAP and UCH-L1 in the older CT- subjects. Levels of GFAP and UCH-L1 were not significantly higher by age in the CT+ subjects. Iverson et al. [96] found both older patients with uncomplicated mTBI and orthopedic controls had higher NF-L levels when blood was drawn within 19 hours of injury. Calcagnile et al. [97] found higher levels of S100B in older patients with mTBI and found that the specificity of the test to identify $\mathrm{CT}+$ patients was reduced in the elderly.

\section{How long do blood biomarker levels remain elevated after mTBI?}

A few studies have examined biomarker levels months or years after mTBI. Blood half-lives of most biomarkers (UCH-L1, S100B, GFAP) are short (less than $48 \mathrm{hrs)}$ [12]. With the exception of NF-L which has a longer halflife, biomarker levels at 30 to 90 days are expected to be normal unless there is ongoing neural degeneration or reinjury . Shahim et al. [98] followed 89 subjects with mTBI for up to five years. In some subjects, they found elevated NF-L levels up to 5 years after mTBI. Levels of GFAP were elevated for up to 30 days after mTBI. Tau and UCHL1 were at baseline levels after 30 days [98]. Shahim et al. [99] found elevated NF-L levels in the cerebrospinal fluid of professional hockey players with post-concussion syndrome for up to one year after mTBI. Pattinson et al. [100] studied 109 military personnel with a past history of traumatic brain injury. They found TBI subjects did not differ from controls in levels of tau, NF-L, $A \beta 40$, or $A \beta 42$. McDonald et al. [68] found elevated blood NF-L levels for up to 13 days after concussion in Australian football players and these levels discriminated concussed players from control players. Bogoslovsky et al. [101] measured levels of amyloid- $\beta 42$, tau, and GFAP at 0,30 , and 90 days after TBI in 34 subjects entered into the COBRIT trial. Subjects were of mixed TBI severity; none had simple concussions. They found elevated levels of three biomarkers compared to controls, although levels of tau and GFAP were dropping. Currently, explanation for persistently elevated biomarker levels after mTBI in some subjects remains uncertain. Persistent elevations of NF-L after mTBI could reflect ongoing release of biomarker from original injury or re-injury [13]. The prognostic significance of these late elevations is uncertain. Upregulation of protein synthesis in some patients after TBI has been reported [102].

\section{Can blood biomarkers diagnose concussive or sub-concussive hits to the head?}

Studies have shown that blood biomarkers have a modest capability to distinguish healthy controls from concussed subjects (Table 4). Most of the areas under the receiver operator curves (AUROC) are below 0.80, suggesting only fair discrimination between healthy controls and concussed subjects. Papa et al. [17] found higher levels of UCH-L1 (AUROC $=0.65)$ and GFAP (AUROC $=0.76)$ in concussed head injury subjects compared to head injury controls without concussion symptoms at 0 to $4 \mathrm{hrs}$. In the 0 to $6 \mathrm{hr}$ time frame, McCrea et al. [31] found only modest values for the AUROC for UCH-L1 (0.66), tau (0.55), NF$\mathrm{L}$ (0.56), and GFAP (0.68). One explanation for these low AUROC levels may be that the response to a concussion 
Table 4 Area under the receiver operator curve (AUROC) for diagnosis of concussion per biomarker

\begin{tabular}{|c|c|c|c|c|c|}
\hline Marker & $\begin{array}{l}\text { Study } \\
\text { Lead Author }\end{array}$ & Year & $\begin{array}{l}\text { Study Size } \\
\text { (N) }\end{array}$ & $\begin{array}{l}\text { Sampling } \\
\text { Time (hrs) } \dagger\end{array}$ & AUROC* \\
\hline \multirow{7}{*}{ GFAP } & Gill [71] & 2018 & 277 & $0-48$ & 0.93 \\
\hline & Papa [17] & 2019 & 452 & $0-4$ & 0.76 \\
\hline & Giza [83] & 2021 & 167 & $0-6$ & 0.75 \\
\hline & Lewis [103] & 2017 & 188 & $0-6$ & 0.70 \\
\hline & McCrea [31] & 2020 & 206 & $0-6$ & 0.68 \\
\hline & Posti [81] & 2017 & 44 & $0-24$ & 0.63 \\
\hline & Asken [79] & 2018 & 29 & $0-4$ & 0.63 \\
\hline \multirow{7}{*}{ NF-L } & McDonald [68] & 2021 & 28 & 2 days & 0.60 \\
\hline & Meier [80] & 2017 & 32 & $0-6$ & 0.53 \\
\hline & McDonald [68] & 2021 & $20 \neq$ & 6 days & 0.85 \\
\hline & Gill [71] & 2018 & 277 & $0-48$ & 0.77 \\
\hline & Giza [83] & 2021 & 167 & $0-6$ & 0.73 \\
\hline & McCrea [31] & 2020 & 206 & $0-6$ & 0.56 \\
\hline & Wallace [104] & 2018 & 12 & 6 days & NS \\
\hline \multirow{4}{*}{ S100B } & Asken [79] & 2018 & 29 & $0-4$ & 0.75 \\
\hline & Meier [80] & 2017 & 32 & $0-6$ & 0.72 \\
\hline & Lewis [103] & 2017 & 188 & $0-6$ & 0.69 \\
\hline & Shahim [85] & 2014 & 35 & $0-1$ & 0.67 \\
\hline \multirow{7}{*}{ tau- $-\mathrm{T}$} & Rogatzi [86] & 2021 & 8 & $0-1$ & 0.48 \\
\hline & Shahim [85] & 2014 & 35 & $0-1$ & 0.86 \\
\hline & Asken [79] & 2018 & 27 & $0-4$ & 0.74 \\
\hline & McDonald [68] & 2021 & $20 \neq$ & 13 days & 0.72 \\
\hline & Gill [71] & 2018 & 277 & $0-48$ & 0.68 \\
\hline & McCrea [31] & 2020 & 206 & $0-6$ & 0.55 \\
\hline & Giza [83] & 2021 & 167 & $0-6$ & 0.50 \\
\hline \multirow{10}{*}{ UCH-L1 } & Wallace [104] & 2018 & 11 & 6 days & NS \\
\hline & Wallace [104] & 2019 & 11 & 14 days & NS \\
\hline & Meier [80] & 2017 & 32 & $0-6$ & 0.74 \\
\hline & Giza [83] & 2021 & 167 & $0-6$ & 0.73 \\
\hline & McCrea [31] & 2020 & 206 & $0-6$ & 0.66 \\
\hline & Lewis [103] & 2017 & 188 & $0-6$ & 0.65 \\
\hline & Papa [17] & 2019 & 452 & $0-4$ & 0.65 \\
\hline & Asken [79] & 2018 & 26 & $0-4$ & 0.62 \\
\hline & McDonald [68] & 2021 & $20 \neq$ & 2 days & 0.61 \\
\hline & Posti [81] & 2017 & 44 & $0-24$ & 0.52 \\
\hline
\end{tabular}

*The bolded AUROC value are $\mathbf{0} \mathbf{0 . 8 0}$.

${ }^{\dagger}$ Times are in hours except where noted.

${ }^{\ddagger}$ Concussed male football players only, NS for 8 females

is bi-modal, with most subjects showing a modest rise in blood biomarker levels and a smaller subset showing a more robust rise in biomarker levels. Bui et al. [29] in their review of data from the CARE mTBI dataset $[30,31]$ that biomarker levels may be bimodal after mTBI, with only a minority of concussed subjects exhibiting large rises in biomarker levels.

Some studies have shown that sub-concussive hits to the head can elevate biomarker levels. For example, Kawata et al. [105] studied S100B levels before and after college 
football practices. None of the subjects sustained a concussion. They compared high-impact to low-impact subjects. Subjects with more hits and hits with higher peak linear and rotational accelerations showed higher levels of S100B. This pattern continued over multiple practices. However, there was no cumulative effect on S100B levels over the season. On the other hand, Hulbregtse et al. [2020], in a controlled randomized trial, compared soccer players who headed or kicked a soccer ball, found no rise in plasma S100B levels at 0,2 , or 24 hrs after 10 headers. Puvenna et al. [14] found that the number of sub-concussive hits during a varsity college football game correlated with S100B levels but not UCH-L1 levels. Over the course of a football season, sub-concussive hits to the head caused no persistent increase in blood tau biomarker levels [106].

\section{Are blood biomarkers predictive of CT scan positivity after mTBI?}

Concussed patients with abnormalities on either MRI or CT scan are termed complicated mTBI [107]. In the CENTER-TBI project, $42.3 \%$ of 2955 subjects with mTBI were classified as complicated mTBI. One goal of blood biomarker research has been to discriminate between patients with abnormalities on $\mathrm{CT}$ scan (CT positive) from subjects without CT scan abnormalities (CT negative). The intent is to identify mTBI patients who are unlikely to benefit from CT scanning. In general, the biomarkers S100B and GFAP have shown a moderate ability to discriminate between CT-positive and CT-negative subjects (Table 5).

Cost savings are possible if patients with mild head injuries who are unlikely to benefit from CT scanning are excluded from neuroimaging. In Europe, S100B has been extensively studied as a biomarker that could reduce the use of CT scanning for minor head injuries [26, 114]. If a cutpoint of $100 \mathrm{pg} / \mathrm{ml}$ is used for S100B within $6 \mathrm{hrs}$ of head injury, the test is $97 \%$ sensitive and $34 \%$ specific in predicting subjects with CT scan abnormalities [26]. A risk occurs with $\mathrm{S} 100 \mathrm{~B}$ due to its short half-life of 1-2 hrs [26], making false-negative tests possible if blood sampling is delayed excessively. However, false-negative tests with S100B have only rarely been reported, and the biggest problem in the use of the test has been low specificity. The most recent validation of the Scandinavian Head Injury Guideline with a cutoff of $100 \mathrm{pg} / \mathrm{ml}$ of S100B within 6 hrs of mild head injury showed a sensitivity of 0.94 and a specificity of 0.19 in predicting abnormalities on CT scan. The lower specificity has been attributed to the greater age of the study group, with older patients having higher baseline levels of S100B [115]. If fully applied, the Scandinavian Guidelines with S100B testing would have reduced CT scanning by $9 \%$ [115]. Jones et al. [111] evaluated the predictive value of S100B for CT abnormalities in $679 \mathrm{mTBI}$ subjects. Blood was drawn within 6 hours of head injury. With a cutoff of $100 \mathrm{pg} / \mathrm{ml}$, they found a sensitivity of 0.85 , a specificity of 0.34 , a positive predictive value of 0.72 , and a negative predictive value of 0.97 for abnormalities on the CT scan after mTBI. Calcagnile et al. [116] measured S100B blood levels within 3 hours of injury in 726 subjects with mTBI. Using a cutoff of $100 \mathrm{pg} / \mathrm{ml}$, they found no subjects with a positive CT scan in the 229 subjects with S100B below the cutoff point and found a positive CT scan in 150 of the 497 subjects with an S100B over the cutoff point. Another study found an S100B level above $100 \mathrm{pg} / \mathrm{ml}$ within 6 hours of injury predictive of CT scan abnormalities [112]. In a meta-analysis of eight published studies, Oris et al. [117] found a pooled sensitivity of $100 \%$ and a pooled specificity of $35 \%$ when S100B levels were obtained within 3 hrs of injury. Cutoff values for S100B varied by study between 6 and 200 pg/ml. Ananthaharan et al. [118] monitored the use of the S100B Scandinavian CT scanning guidelines in mTBI. In 69 subjects with a mTBI and S100B level below the cutoff of $100 \mathrm{pg} / \mathrm{ml}$, all had a negative CT scan.

In the United States, the FDA has approved the Banyan $\mathrm{BTI}^{\mathrm{Tm}}$ (Brain Trauma Indicator) to predict CT scan abnormalities after mTBI. Blood is sampled within $12 \mathrm{hrs}$ of head injury. Test sensitivity is $97.5 \%$ and specificity is $36.5 \%$ on the FDA application [119]. The FDA has recently approved a handheld testing platform for GFAP and UCH-L1 levels with results available within 15 mins [120]. Okonkwo et al. [121] have reported on the point of care testing of 1359 traumatic brain injury subjects of all severity levels. The AUROC for prediction of a positive CT scan for GFAP (0.85) was significantly higher than S100B (0.67) for subjects evaluated within 24 hr of injury.

Gill et al. [71] studied 277 subjects with suspected mTBI in the emergency room setting. Levels of UCH-L1, NF-L, tau, and GFAP were measured by single-molecule array assay. By AUROC, GFAP outperformed tau and NF-L in predicting neuroimaging abnormalities (CT or MRI). Another study, done with the less sensitive ELISA assay, suggested that GFAP was a better predictor of CT scan abnormalities than S100B [122]. The TRACK-TBI study evaluated $450 \mathrm{mTBI}$ subjects who were CT scan negative. GFAP levels were higher in MRI positive mTBI subjects than MRI negative subjects. Both groups of mTBI were significantly higher than orthopedic controls or healthy controls [82]. Another study confirmed the ability of GFAP to discriminate between $\mathrm{CT}$ positive and CT negative subjects with mTBI [109]. Lewis et al. [103] evaluated the ability of GFAP, UCH-L1, and S100B to stratify 247 emergency room patients who had biomarker levels within 6 hrs of injury. All three biomarkers were higher in subjects with complicated mTBI than mTBI and higher in mTBI than no TBI. A cutoff of $30 \mathrm{pg} / \mathrm{ml}$ for GFAP, $30 \mathrm{pg} / \mathrm{ml}$ for $\mathrm{UCH}-\mathrm{L} 1$, and $35 \mathrm{pg} / \mathrm{ml}$ for $\mathrm{S} 100 \mathrm{~B}$ gave a 
Table 5 Area under the receiver operator curve (AUROC) for CT positivity by biomarker

\begin{tabular}{|c|c|c|c|c|c|}
\hline Marker & $\begin{array}{l}\text { Study } \\
\text { Lead Author }\end{array}$ & Year & $\begin{array}{l}\text { Study Size } \\
\text { (N) }\end{array}$ & $\begin{array}{l}\text { Sampling } \\
\text { Time (hrs) }\end{array}$ & AUROC \\
\hline & Czeiter [108] & 2020 & $2867 \neq$ & $0-24$ & 0.89 \\
\hline & Gardner [94] & 2018 & 169 & $0-24$ & 0.88 \\
\hline & Huebschmann [109] & 2020 & 121 & $0-12$ & 0.81 \\
\hline \multirow[t]{4}{*}{ GFAP } & Welch [65] & 2016 & 251 & $0-6$ & 0.78 \\
\hline & Gill [71] & 2018 & 277 & $0-48$ & 0.77 \\
\hline & Yue [82]* & 2019 & 450 & $0-24$ & 0.77 \\
\hline & Lewis [103] & 2017 & 188 & $0-6$ & 0.66 \\
\hline \multirow[t]{3}{*}{ NF-L } & Gill [71] & 2018 & 277 & $0-48$ & 0.65 \\
\hline & Welch [65] & 2016 & 251 & $0-6$ & 0.75 \\
\hline & Allouchery [110] & 2018 & 1449 & $0-2$ & 0.72 \\
\hline \multirow{4}{*}{ S100B } & Jones [111] & 2020 & 679 & $0-6$ & 0.69 \\
\hline & Egea-Guerrero [112] & 2018 & 260 & $0-6$ & 0.67 \\
\hline & Lewis [103] & 2017 & 188 & $0-6$ & 0.65 \\
\hline & Yue [82]* & 2019 & 450 & $0-24$ & 0.56 \\
\hline \multirow[t]{2}{*}{ tau-P } & Gardner [94] & 2018 & 169 & $0-24$ & 0.93 \\
\hline & Gardner [94] & 2018 & 169 & $0-24$ & 0.71 \\
\hline \multirow[t]{3}{*}{ tau- $\mathrm{T}$} & Diaz-Arrastia [113] & 2014 & 171 & $0-24$ & 0.67 \\
\hline & Gill [71] & 2018 & 277 & $0-48$ & 0.66 \\
\hline & Welch [65] & 2016 & 251 & $0-6$ & 0.79 \\
\hline \multirow[t]{2}{*}{ UCH-L1 } & Lewis [103] & 2017 & 188 & $0-6$ & 0.60 \\
\hline & Yue [82]* & 2019 & 450 & $0-24$ & 0.59 \\
\hline
\end{tabular}

The bolded AUROC values are $\geq \mathbf{0 . 8 0}$

*This study compared MR- vs. MRI+ in CT- subjects. All other studies are CT- vs. CT+

${ }^{\dagger} 1951$ of 2867 subjects had mTBI.

${ }^{\ddagger}$ Concussed male football players only, females excluded.

sensitivity of $44 \%$ for GFAP, $95 \%$ for UCH-L1, and $96 \%$ for S100B in distinguishing between no TBI and mTBI. Cutoffs for distinguishing between complicated mTBI and mTBI were not provided.

\section{Are blood biomarkers predictive of severity and outcome after $\mathrm{mTBI}$ ?}

Several clinical measures have been used to assess the clinical severity of mTBI including the SAC (Standardized Assessment of Concussion), the SCAT (Sports Concussion Assessment Tool), the BESS (Balance Error Scoring System), BSI-18 (Brief Symptom Inventory-18), and the ImPACT (Immediate Post-Concussion Assessment and Cognitive Test (ImPACT). In general, few correlations have been found between these clinical measures and blood biomarker levels after mild TBI [29, 31, 68, 79, 83]. Giza et al. [83] found a weak correlation $(r=0.36)$ between acute GFAP levels and the BESS. Bui et al. [29] examined clustering of biomarker trajectories for tau, UCH-L1, GFAP, and NF-L. In general biomarker trajectory did not predict TBI severity with three exceptions: clusters with higher trajectories of NF-L and GFAP did worse on the $\mathrm{SAC}$ at $6 \mathrm{hrs}$ post mTBI, and a cluster with higher UCHL1 did worse on the verbal memory test at 7 days after post return to sport. Nonetheless, the limited capacity of blood biomarkers to correlate with mTBI severity has been disappointing to date.

The prediction of outcome after mTBI has been difficult, whether the outcome is measured by the time to recovery, the persistence of symptoms, or the development of a post-concussion syndrome (PCS). Accurate models to predict outcome from mTBI are not available [123]. As assessed by AUROC, blood biomarkers are weakly predictive of outcome after mTBI (Table 6). Both NF-L and tau have shown a limited predictive ability for return to sport in professional hockey players after concussion [67, 72, 84, 85]. NF-L levels measured up to 144 hours after injury and tau measured up to 12 hours after injury were predictive of return to sport [71, 72, 85]. A small study did not find cleaved tau levels predictive of post-concussion syndrome [127]. Gill et al. [87] found higher tau levels in student athletes with a prolonged 
Table 6 Area under the receiver operator curve (AUROC) for biomarker studies predicting outcome from mTBI

\begin{tabular}{|c|c|c|c|c|c|c|}
\hline \multirow[t]{2}{*}{ Marker } & \multirow[t]{2}{*}{ Study } & \multirow[t]{2}{*}{ Year } & \multirow[t]{2}{*}{$N$} & \multirow[t]{2}{*}{ Time (hrs) } & \multirow[t]{2}{*}{ AUROC } & \multirow{2}{*}{$\begin{array}{l}\text { Outcome } \\
\text { Predicted }\end{array}$} \\
\hline & & & & & & \\
\hline \multirow{2}{*}{ GFAP } & Huebschmann [109] & 2020 & 121 & $0-12$ & 0.69 & GOS-E $>6$ \\
\hline & Pattinson [124] & 2020 & 59 & $0-12$ & 0.40 & RTS $<8$ days \\
\hline \multirow{2}{*}{$N F-L$} & Shahim [72] & 2018 & 87 & $0-1$ & 0.83 & RTS $<15$ days \\
\hline & Shahim [84] & 2017 & 35 & $0-1$ & 0.82 & RTS $<6$ days \\
\hline \multirow{2}{*}{ S100B } & Shahim [85] & 2014 & 28 & $0-1$ & 0.68 & Duration of $\mathrm{PCS}<6$ days \\
\hline & Babcock [125] & 2008 & 76 & $0-6$ & 0.47 & Onset of PCS \\
\hline tau-A & Shahim [67] & 2016 & 28 & $0-1$ & 0.87 & RTS $<10$ days \\
\hline tau-C & Shahim [67] & 2016 & 28 & $0-1$ & 0.58 & RTS $<10$ days \\
\hline \multirow{6}{*}{ tau- $T$} & Shahim [85] & 2014 & 28 & $0-1$ & 0.91 & Duration of $\mathrm{PCS}<6$ days \\
\hline & Gill [87] & 2017 & 43 & $0-6$ & 0.81 & RTS $<10$ days \\
\hline & Pattinson [124] & 2020 & 59 & Recovered & 0.75 & RTS $<8$ days \\
\hline & Shahim [72] & 2018 & 87 & $0-1$ & 0.67 & RTS $<15$ days \\
\hline & Pattinson [124] & 2020 & 55 & $24-48$ & 0.66 & RTS $<8$ days \\
\hline & Hossain [126] & 2020 & 105 & $0-24$ & 0.56 & GOS-E $>7$ \\
\hline
\end{tabular}

RTS Return to sport.

bolded AUROC values $\geq \mathbf{0 . 8 0}$

return to sport after sports-related concussion. In a larger study, Pattinson et al. [124] studied 127 concussed student athletes and found that early tau levels were weakly predictive of return to sport. Similarly, Hossain et al. [126] found a weak correlation between admission tau levels and Glasgow Outcome Scale-Extended score at 6-12 months.

\section{Conclusions}

This review examined eight unresolved issues related to the use of blood biomarkers for the diagnosis and management of mTBI. A number of review limitations should be emphasized. We focused on the five most commonly investigated blood biomarkers after mTBI and did not address other blood biomarkers such as neuron specific enolase (NSE), myelin basic protein, inflammatory biomarkers, or microRNA [128]. Our review methodology was a focused and not systematic. We have used the more general term blood biomarker level and have not distinguished between plasma and serum levels (although plasma and serum levels differ, they are generally highly correlated [129]). Analytic issues such as test-retest reliability, test sensitivity, inconsistencies across test platforms, and issues related to storage and handling of samples have not been addressed in this work (for a discussion of some of these issues see [13]. We focused on blood levels of biomarkers and did not address biomarker levels in the cerebrospinal fluid, urine, or saliva [130, 131].

Evidence from the clinical setting and from animal models indicates a disruption of the blood brain barrier occurs after moderate to severe traumatic brain injury [132-136, 136-139] and that biomarkers can cross the blood brain barrier into the blood [11, 62]. In mTBI, the blood brain barrier may be disrupted as well [132, 137]. Nonetheless, a disruption of the blood brain barrier may not be essential for the entry of biomarkers into the blood. Opinion is growing that protein biomarkers enter the blood by alternate routes [15] including the intramural periarterial drainage system and the glymphatic system. The route of entry by biomarkers, whether by crossing the blood brain barrier, through glymphatics, or via other drainage pathways, likely influences the rate of absorption and kinetics of blood biomarkers for mTBI.

Kinetic parameters such as $T_{\max }$ and half-life provide important information about the behavior of mTBI biomarkers in the blood. Current estimates of these kinetic parameters are imprecise [13]. Better estimates of kinetic parameters would allow more precise modeling of biomarker levels after TBI and foster more precise cutoff levels and sampling times. Available evidence suggests that the optimal sampling time for $\mathrm{S} 100 \mathrm{~B}$ after mTBI is between 1 and 3 hours, for tau and UCH-L1 optimal sampling time is likely between 2 and 8 hours. The optimal sampling time for GFAP is likely later, possibly between 6 and 18 hours. There is less certainty about the optimal sampling time for NF-L due to uncertainty about biomarker half-live and $\mathrm{T}_{\max }$, but it is likely later than the other commonly measured biomarkers for mTBI. Several confounding factors for blood biomarker levels have been identified including increasing age, renal 
failure, and increased blood volume. However, corrections in biomarker levels are not routinely made for these confounding factors. Elevated levels of both tau and NF-L have been observed months or years after traumatic brain injury. The significance of these persistent elevations in blood biomarker levels is uncertain.

Blood biomarkers have a modest ability to detect subconcussive head injuries and a modest ability to discriminate between concussed and non-concussed subjects. Some subjects with verified concussions may have minimal increases in blood biomarker levels which overlap with the levels found in control subjects. None of the studied blood biomarkers have been shown to reliably correlate with repetitive sub-concussive hits or cumulative concussive hits to the head. Blood biomarkers have had some success in predicting $\mathrm{CT}$ scan positivity after mild traumatic brain injury. S100B is widely used in Europe, and the GFAP/UCH-L1 tandem test has been approved for use in the United States. Despite impressive levels of sensitivity, these tests lack high levels of specificity. Correlations between blood biomarker levels and mTBI severity have been disappointing to date. Evidence is inconclusive as to whether any blood biomarker predicts recovery time, post-concussion syndrome, or return to sport after mild traumatic brain injury. Both tau and neurofilament light chain protein have shown limited promise for this application. Return to sport and return to work decisions are influenced by complex educational, sociological, and psychological factors not captured in a blood biomarker test [140].

\section{Abbreviations \\ AUROC: Area under receiver operator curve; CARE: Concussion Assessment, Research, and Education Consortium Study; CENTER-TBI: Collaborative European NeuroTrauma Effectiveness Research in Traumatic Brain Injury; CT- $C T$ negative (without findings); $C T+$ : $C T$ positive (with findings); GFAP: glial acidic fibrillary protein; NF-L: neurofilament light chain; PCS: post-concussion syndrome; RTS: Return to sport; tau-C: cleaved tau; tau-P: phosphorylated tau; tau-T: total tau; TBI traumatic brain injury; UCH-L1: ubiquitin C-terminal hydrolase-L1}

\section{Acknowledgments}

The authors thank Lien A. Bui, Zachary Roy, Louis Steinmeister, and Dacosta Yeboah for their participation in ongoing discussions related to this work.

\section{Authors' contributions}

Concept by DBH. Issue formulation by all authors. The literature review by all authors. Issue analysis by all authors. Manuscript drafting, revising, and final approval by all authors. The authors read and approved the final manuscript.

\section{Funding}

Research was partially sponsored by the Mary K. Finley Missouri Endowment, the Missouri S\&T Intelligent Systems Center, the National Science Foundation and the Leonard Wood Institute in cooperation with the U.S. Army Research Laboratory and was accomplished under Cooperative Agreement Number W91 1NF-14-2-0034. Additional support came from NIH Award R15 GM117507-01A1. The views, opinions, findings, recommendations or conclusions contained in this document are those of the authors and should not be interpreted as representing the views or official policies, either expressed or implied, of the Leonard Wood Institute, the Army Research Laboratory, the National Science Foundation or the U.S. Government. The U.S. Government is authorized to reproduce and distribute reprints for Government purposes, notwithstanding any copyright notation hereon.
Availability of data and materials

Not applicable.

\section{Declarations}

Ethics approval and consent to participate

Not applicable.

\section{Consent for publication}

Not applicable.

\section{Competing interests}

The authors declare that they have no competing interests.

\section{Author details}

${ }^{1}$ Department of Electrical and Computer Engineering, Missouri University of Science and Technology, Rolla MO 65401, USA. ${ }^{2}$ Cooperative Engineering Program, Missouri State University, Springfield MO 65897, United States. ${ }^{3}$ Department of Biological Sciences, Missouri University of Science and Technology, Rolla MO 65409, United States. ${ }^{4}$ Department of Mathematics and Statistics, Missouri University of Science and Technology, Rolla MO 65409, United States. ${ }^{5}$ Department of Surgery, Mercy Hospital, St. Louis MO, Missouri MO 63141, United States. ${ }^{6}$ National Science Foundation, ECCS Division, Virginia 22314, USA.

Received: 4 March 2021 Accepted: 26 August 2021

Published online: 16 September 2021

\section{References}

1. Zetterberg $\mathrm{H}$, Blennow K. Fluid biomarkers for mild traumatic brain injury and related conditions. Nat Rev Neurol. 2016;12(10):563-74.

2. Kulbe JR, Geddes JW. Current status of fluid biomarkers in mild traumatic brain injury. Exp Neurol. 2016;275:334-52

3. Agoston DV, Shutes-David A, Peskind ER. Biofluid biomarkers of traumatic brain injury. Brain Inj. 2017;31(9):1195-203.

4. Zetterberg $\mathrm{H}$, Smith DH, Blennow K. Biomarkers of mild traumatic brain injury in cerebrospinal fluid and blood. Nat Rev Neurol. 2013;9(4):201.

5. Wang KK, Yang Z, Zhu T, Shi Y, Rubenstein R, Tyndall JA, Manley GT. An update on diagnostic and prognostic biomarkers for traumatic brain injury. Expert Rev Mol Diagn. 2018;18(2):165-80.

6. Papa L, Ramia MM, Edwards D, Johnson BD, Slobounov SM. Systematic review of clinical studies examining biomarkers of brain injury in athletes after sports-related concussion. J Neurotrauma. 2015;32(10):661-73.

7. Mehta T, Fayyaz M, Giler GE, Kaur H, Raikwar SP, Kempuraj D, Selvakumar GP, Ahmed ME, Thangavel R, Zaheer S, et al. Current trends in biomarkers for traumatic brain injury. Open Access J Neurol Neurosurg. 2020;12(4):86.

8. Manivannan S, Makwana M, Ahmed Al, Zaben M. Profiling biomarkers of traumatic axonal injury: from mouse to man. Clin Neurol Neurosurg. 2018;171:6-20.

9. Adrian $\mathrm{H}$, Mårten $\mathrm{K}$, Salla N, Lasse V. Biomarkers of traumatic brain injury: temporal changes in body fluids. Eneuro. 2016;3(6)ENEURO.0294-16.2016. https://doi.org/10.1523/ENEURO.029416.2016 .

10. Bogoslovsky T, Gill J, Jeromin A, Davis C, Diaz-Arrastia R. Fluid biomarkers of traumatic brain injury and intended context of use. Diagnostics. 2016;6(4):37.

11. Kawata K, Liu CY, Merkel SF, Ramirez SH, Tierney RT, Langford D. Blood biomarkers for brain injury: what are we measuring? Neurosci Biobehav Rev. 2016:68:460-73.

12. Thelin EP, Zeiler FA, Ercole A, Mondello S, Büki A, Bellander B-M, Helmy A, Menon DK, Nelson DW. Serial sampling of serum protein biomarkers for monitoring human traumatic brain injury dynamics: a systematic review. Front Neurol. 2017;8:300.

13. McDonald SJ, Shultz SR, Agoston DV. The known unknowns: An overview of the state of blood-based protein biomarkers of mild traumatic brain injury. J Neurotrauma. 2021. https://doi.org/10.1089/ neu.2021.0011.

14. Potokar M, Morita M, Wiche G, Jorgačevski J. The diversity of intermediate filaments in astrocytes. Cells. 2020;9(7):1604.

15. Yang Z, Wang KK. Glial fibrillary acidic protein: from intermediate filament assembly and gliosis to neurobiomarker. Trends Neurosci. 2015;38(6):364-74. 
16. Neselius S, Brisby $H$, Theodorsson A, Blennow K, Zetterberg $H$, Marcusson J. Csf-biomarkers in olympic boxing: diagnosis and effects of repetitive head trauma. PloS ONE. 2012;7(4):33606.

17. Papa L, Zonfrillo MR, Welch RD, Lewis LM, Braga CF, Tan CN, Ameli NJ, Lopez MA, Haeussler CA, Giordano DM, et al. Evaluating glial and neuronal blood biomarkers GFAP and Uch-L1 as gradients of brain injury in concussive, subconcussive and non-concussive trauma: a prospective cohort study. BMJ Paediatrics Open. 2019;3(1):e000473. https://doi.org/ 10.1136/bmjpo-2019-000473.

18. Barry DM, Millecamps S, Julien J-P, Garcia ML. New movements in neurofilament transport, turnover and disease. Exp Cell Res. 2007:313(10):2110-20

19. Yuan A, Rao MV, Nixon RA, et al. Neurofilaments at a glance. J Cell Sci. 2012;125(14):3257-63.

20. Khalil M, Teunissen CE, Otto M, Piehl F, Sormani MP, Gattringer T, Barro C, Kappos L, Comabella M, Fazekas F, et al. Neurofilaments as biomarkers in neurological disorders. Nat Rev Neurol. 2018;14(10): $577-89$.

21. Gao W, Zhang Z, Lv X, Wu Q, Yan J, Mao G, Xing W. Neurofilament light chain level in traumatic brain injury: a system review and meta-analysis. Medicine. 2020:99(38). https://doi.org/10.1097/MD.0000000000022363.

22. Brophy GM, Mondello S, Papa L, Robicsek SA, Gabrielli A, Tepas III J, Buki A, Robertson C, Tortella FC, Hayes RL, et al. Biokinetic analysis of ubiquitin c-terminal hydrolase-L1 (UCH-L1) in severe traumatic brain injury patient biofluids. J Neurotrauma. 2011;28(6):861-70.

23. Hanes J, Zilka N, Bartkova M, Caletkova M, Dobrota D, Novak M. Rat tau proteome consists of six tau isoforms: Implication for animal models of human tauopathies. J Neurochem. 2009;108(5):1167-76. https://doi. org/10.1111/j.1471-4159.2009.05869.x.

24. Sato C, Barthélemy NR, Mawuenyega KG, Patterson BW, Gordon BA, Jockel-Balsarotti J, Sullivan M, Crisp MJ, Kasten T, Kirmess KM, et al. Tau kinetics in neurons and the human central nervous system. Neuron. 2018;97(6):1284-98.

25. Rubenstein R, Chang B, Davies P, Wagner AK, Robertson CS, Wang KK. A novel, ultrasensitive assay for tau: potential for assessing traumatic brain injury in tissues and biofluids. J Neurotrauma. 2015;32(5):342-52.

26. Thelin EP, Nelson DW, Bellander B-M. A review of the clinical utility of S100B protein levels in the assessment of traumatic brain injury. Acta Neurochir. 2017;159(2):209-25.

27. Townend W, Dibble C, Abid K, Vail A, Sherwood R, Lecky F. Rapid elimination of protein s-100b from serum after minor head trauma. J Neurotrauma. 2006;23(2):149-55.

28. Jönsson $\mathrm{H}$, Johnsson $\mathrm{P}$, Höglund $\mathrm{P}$, Alling $\mathrm{C}$, Blomquist $\mathrm{S}$. Elimination of S100B and renal function after cardiac surgery. J Cardiothorac Vasc Anesth. 2000;14(6):698-701.

29. Bui LA, Yeboah D, Steinmaster L, Azizi S, Hier D, Wunsch D, Olbricht GR, Obafemi-Ajayi T. Heterogeneity in blood biomarker trajectories after mild TBI revealed by unsupervised learning. IEEE/ACM Trans Comput Biol Bioinforma. 2021

30. Broglio SP, McCrea M, McAllister T, Harezlak J, Katz B, Hack D, Hainline $B$, Investigators CC, et al. A national study on the effects of concussion in collegiate athletes and us military service academy members: the NCAA-DOD concussion assessment, research and education (CARE) consortium structure and methods. Sports Med. 2017:47(7):1437-51.

31. McCrea M, Broglio SP, McAllister TW, Gill J, Giza CC, Huber DL, Harezlak J, Cameron KL, Houston MN, McGinty G, et al. Association of blood biomarkers with acute sport-related concussion in collegiate athletes: findings from the NCAA and Department of Defense CARE consortium. JAMA Netw Open. 2020;3(1):1919771.

32. Federal Interagency Traumatic Brain Injury Research (FITBIR). https:// fitbir.nih.gov/. Accessed 08 Sep 2021.

33. Wolak DJ, Thorne RG. Diffusion of macromolecules in the brain: implications for drug delivery. Mol Pharm. 2013;10(5):1492-504.

34. Nakada T, Kwee IL. Fluid dynamics inside the brain barrier: current concept of interstitial flow, glymphatic flow, and cerebrospinal fluid circulation in the brain. Neuroscientist. 2019;25(2):155-66.

35. Shetty AK, Zanirati G. The interstitial system of the brain in health and disease. Aging Dis. 2020;11(1):200-11. https://doi.org/10.14336/AD. 2020.0103

36. UniProt Consortium. UniProt: a worldwide hub of protein knowledge. Nucleic Acids Res. 2019;47(D1):506-15.
37. Lei $Y$, Han H, Yuan F, Javeed A, Zhao Y. The brain interstitial system: Anatomy, modeling, in vivo measurement, and applications. Prog Neurobiol. 2017;157:230-46.

38. Hay JR, Johnson VE, Young AM, Smith DH, Stewart W. Blood-brain barrier disruption is an early event that may persist for many years after traumatic brain injury in humans. J Neuropathol Exp Neurol. 2015;74(12): 1147-57.

39. Saw MM, Chamberlain J, Barr M, Morgan MP, Burnett JR, Ho KM Differential disruption of blood-brain barrier in severe traumatic brain injury. Neurocrit Care. 2014;20(2):209-16.

40. Turtzo LC, Jikaria N, Cota MR, Williford JP, Uche V, Davis T, MacLaren J, Moses AD, Parikh G, Castro MA, et al. Meningeal blood-brain barrier disruption in acute traumatic brain injury. Brain Commun. 2020;2(2):143.

41. Cushing $\mathrm{H}$, et al. The third circulation and its channels. Lancet. 1925;2: 851-7.

42. Milhorat TH. The third circulation revisited. J Neurosurg. 1975;42(6): 628-45.

43. Johanson CE, Duncan JA, Klinge PM, Brinker T, Stopa EG, Silverberg GD. Multiplicity of cerebrospinal fluid functions: new challenges in health and disease. Cerebrospinal Fluid Res. 2008;5(1):10.

44. Knopf P, Cserr H, Nolan S, Wu T, Harling-Berg C. Physiology and immunology of lymphatic drainage of interstitial and cerebrospinal fluid from the brain. Neuropathol Appl Neurobiol. 1995;21(3):175-80.

45. Boulton M, Flessner M, Armstrong D, Hay J, Johnston M. Lymphatic drainage of the cns: effects of lymphatic diversion/ligation on csf protein transport to plasma. Am J Physiol Regul Integr Comp Physiol. 1997;272(5):1613-9.

46. Albargothy NJ, Johnston DA, MacGregor-Sharp M, Weller RO, Verma A, Hawkes CA, Carare RO. Convective influx/glymphatic system: tracers injected into the csf enter and leave the brain along separate periarterial basement membrane pathways. Acta Neuropathol. 2018;136(1):139-52.

47. Schley D, Carare-Nnadi R, Please C, Perry V, Weller R. Mechanisms to explain the reverse perivascular transport of solutes out of the brain. J Theor Biol. 2006;238(4):962-74

48. Weller RO, Kida S, Zhang E-T. Pathways of fluid drainage from the brain-morphological aspects and immunological significance in rat and man. Brain Pathol. 1992;2(4):277-84.

49. Zhang E, Richards H, Kida S, Weller R. Directional and compartmentalised drainage of interstitial fluid and cerebrospinal fluid from the rat brain. Acta Neuropathol. 1992;83(3):233-9.

50. Nimmo J, Johnston DA, Dodart J, MacGregor-Sharp MT, Weller RO, Nicoll JA, Verma A, Carare RO. Peri-arterial pathways for clearance of $\alpha$-synuclein and tau from the brain: Implications for the pathogenesis of dementias and for immunotherapy. Alzheimers Dement: Diagn Assess Dis Monit. 2020;12(1):12070.

51. Nedergaard M. Garbage truck of the brain. Science. 2013;340(6140): 1529-30.

52. Jessen NA, Munk ASF, Lundgaard I, Nedergaard M. The glymphatic system: a beginner's guide. Neurochem Res. 2015;40(12):2583-99.

53. Iliff JJ, Wang M, Liao Y, Plogg BA, Peng W, Gundersen GA, Benveniste $H$ Vates GE, Deane R, Goldman SA, et al. A paravascular pathway facilitates CSF flow through the brain parenchyma and the clearance of interstitial solutes, including amyloid $\beta$. Sci Transl Med. 2012;4(147):111147111.

54. Plog BA, Nedergaard M. The glymphatic system in central nervous system health and disease: past, present, and future. Annu Rev Pathol: Mech Dis. 2018;13:379-94.

55. Ray L, lliff JJ, Heys JJ. Analysis of convective and diffusive transport in the brain interstitium. Fluids Barriers CNS. 2019;16(1):6.

56. Plog BA, Dashnaw ML, Hitomi E, Peng W, Liao Y, Lou N, Deane R, Nedergaard M. Biomarkers of traumatic injury are transported from brain to blood via the glymphatic system. J Neurosci. 2015;35(2):518-26.

57. Patel TK, Habimana-Griffin L, Gao X, Xu B, Achilefu S, Alitalo K, McKee CA, Sheehan PW, Musiek ES, Xiong C, et al. Dural lymphatics regulate clearance of extracellular tau from the CNS. Mol Neurodegener. 2019;14(1):11.

58. Bacyinski A, Xu M, Wang W, Hu J. The paravascular pathway for brain waste clearance: current understanding, significance and controversy. Front Neuroanat. 2017;11:101.

59. Hladky SB, Barrand MA. Mechanisms of fluid movement into, through and out of the brain: evaluation of the evidence. Fluids Barriers CNS. 2014;11(1):26. 
60. Dadas A, Washington J, Marchi N, Janigro D. Improving the clinical management of traumatic brain injury through the pharmacokinetic modeling of peripheral blood biomarkers. Fluids Barriers CNS. 2016;13(1):21.

61. Dadas A, Washington J, Diaz-Arrastia R, Janigro D. Biomarkers in traumatic brain injury (TBI): a review. Neuropsychiatr Dis Treat. 2018;14:2989.

62. Dadas A, Janigro D. The role and diagnostic significance of cellular barriers after concussive head trauma. Concussion. 2018;3(1):53.

63. Knauf MJ, Bell DP, Hirtzer P, Luo Z-P, Young JD, Katre NV. Relationship of effective molecular size to systemic clearance in rats of recombinant interleukin-2 chemically modified with water-soluble polymers. J Biol Chem. 1988;263(29):15064-70.

64. Rosenbaum SE. Basic Pharmacokinetics and Pharmacodynamics: An Integrated Textbook and Computer Simulations. Hoboken, NJ: John Wiley \& Sons; 2016.

65. Welch RD, Ellis M, Lewis LM, Ayaz SI, Mika VH, Millis S, Papa L. Modeling the kinetics of serum glial fibrillary acidic protein, ubiquitin carboxyl-terminal hydrolase-11, and S100B concentrations in patients with traumatic brain injury. J Neurotrauma. 2017;34(11):1957-71.

66. Ercole A, Thelin E, Holst A, Bellander B, Nelson D. Kinetic modelling of serum S100B after traumatic brain injury. BMC Neurology. 2016;16(1):1-8.

67. Shahim $P$, Linemann T, Inekci D, Karsdal MA, Blennow K, Tegner Y, Zetterberg $H$, Henriksen K. Serum tau fragments predict return to play in concussed professional ice hockey players. J Neurotrauma. 2016:33(22):1995-9.

68. McDonald SJ, O'Brien WT, Symons GF, Chen Z, Bain J, Major BP, Costello D, Yamakawa G, Sun M, Brady RD, et al. Prolonged elevation of serum neurofilament light after concussion in male australian football players. Biomarker Res. 2021;9(1):1-9.

69. Ghanem G, Loir B, Morandini R, Sales F, Lienard D, Eggermont A, Lejeune $F$. On the release and half-life of s100b protein in the peripheral blood of melanoma patients. Int J Cancer. 2001;94(4):586-90.

70. Huang M, Dong X-Q, Hu Y-Y, Yu W-H, Zhang Z-Y. High S100B levels in cerebrospinal fluid and peripheral blood of patients with acute basal ganglial hemorrhage are associated with poor outcome. World J Emerg Med. 2010;1(1):22.

71. Gill J, Latour L, Diaz-Arrastia R, Motamedi V, Turtzo C, Shahim P, Mondello S, DeVoto C, Veras E, Hanlon D, et al. Glial fibrillary acidic protein elevations relate to neuroimaging abnormalities after mild TBI. Neurology. 2018;91(15):1385-9.

72. Shahim P, Tegner $Y$, Marklund N, Blennow K, Zetterberg $\mathrm{H}$. Neurofilament light and tau as blood biomarkers for sports-related concussion. Neurology. 2018;90(20):1780-8.

73. Öhrfelt A, Johansson P, Wallin A, Andreasson U, Zetterberg H, Blennow K, Svensson J. Increased cerebrospinal fluid levels of ubiquitin carboxyl-terminal hydrolase L1 in patients with alzheimer's disease. Dement Geriatr Cogn Disord Extra. 2016;6(2):283-94.

74. Azizi S, Hier DB, Allen B, Obafemi-Ayayi T, Olbricht G, Thimgan M, Wunsch DC. A kinetic model for blood biomarker levels after mild traumatic brain injury. Front Neurol. 2021;12:1121

75. Zetterberg H, Bendlin BB. Biomarkers for alzheimer's disease-preparing for a new era of disease-modifying therapies. Mol Psychiatry. 2021;26(1): 296-308. https://doi.org/10.1038/s41380-020-0721-9.

76. Varhaug KN, Torkildsen $\varnothing$, Myhr K-M, Vedeler CA. Neurofilament light chain as a biomarker in multiple sclerosis. Front Neurol. 2019;10:338.

77. Meeter LH, Kaat LD, Rohrer JD, Van Swieten JC. Imaging and fluid biomarkers in frontotemporal dementia. Nat Rev Neurol. 2017;13(7):406

78. Gendron TF, Badi MK, Heckman MG, Jansen-West KR, Vilanilam GK Johnson PW, Burch AR, Walton RL, Ross OA, Brott TG, et al. Plasma neurofilament light predicts mortality in patients with stroke. Sci Trans Med. 2020;12(569). https://doi.org/10.1126/scitranslmed.aay1913.

79. Asken BM, Bauer RM, DeKosky ST, Svingos AM, Hromas G, Boone JK, DuBose DN, Hayes RL, Clugston JR. Concussion Basics III: serum biomarker changes following sport-related concussion. Neurology. 2018;91(23):2133-43.

80. Meier TB, Nelson LD, Huber DL, Bazarian JJ, Hayes RL, McCrea MA. Prospective assessment of acute blood markers of brain injury in sport-related concussion. J Neurotrauma. 2017:34(22):3134-42.

81. Posti JP, Hossain I, Takala RS, Liedes H, Newcombe V, Outtrim J, Katila AJ, Frantzén J, Ala-Seppälä H, Coles JP, et al. Glial fibrillary acidic protein and ubiquitin c-terminal hydrolase-L1 are not specific biomarkers for mild ct-negative traumatic brain injury. J Neurotrauma. 2017;34(7):1427-38.
82. Yue JK, Yuh EL, Korley FK, Winkler EA, Sun X, Puffer RC, Deng H, Choy W, Chandra A, Taylor SR, et al. Association between plasma GFAP concentrations and mri abnormalities in patients with ct-negative traumatic brain injury in the track-TBI cohort: a prospective multicentre study. Lancet Neurol. 2019;18(10):953-61.

83. Giza CC, McCrea M, Huber D, Cameron KL, Houston MN, Jackson JC, McGinty G, Pasquina P, Broglio SP, Brooks A, et al. Assessment of blood biomarker profile after acute concussion during combative training among us military cadets: a prospective study from the ncaa and us department of defense care consortium. JAMA Netw Open. 2021;4(2): 2037731.

84. Shahim P, Zetterberg H, Tegner $Y$, Blennow K. Serum neurofilament light as a biomarker for mild traumatic brain injury in contact sports. Neurology. 2017:88(19):1788-94.

85. Shahim $P$, Tegner $Y$, Wilson DH, Randall J, Skillbäck T, Pazooki D, Kallberg B, Blennow K, Zetterberg H. Blood biomarkers for brain injury in concussed professional ice hockey players. JAMA Neurol. 2014;71(6): 684-92.

86. Rogatzki MJ, Morgan JE, Baker JS, Knox A, Serrador JM. Protein s100b and brain lipid-binding protein concentrations in the serum of recently concussed rugby players. J Neurotrauma. 2021.

87. Gill J, Merchant-Borna K, Jeromin A, Livingston W, Bazarian J. Acute plasma tau relates to prolonged return to play after concussion. Neurology. 2017;88(6):595-602.

88. Mandrekar JN. Receiver operating characteristic curve in diagnostic test assessment. J Thorac Oncol. 2010;5(9):1315-6.

89. Manouchehrinia A, Piehl F, Hillert J, Kuhle J, Alfredsson L, Olsson T, Kockum I. Confounding effect of blood volume and body mass index on blood neurofilament light chain levels. Ann Clin Transl Neurol. 2020;7(1): 139-43.

90. Akamine S, Marutani N, Kanayama D, Gotoh S, Maruyama R, Yanagida K, Sakagami Y, Mori K, Adachi H, Kozawa J, et al. Renal function is associated with blood neurofilament light chain level in older adults. Sci Rep. 2020;10(1):1-7.

91. Khalil M, Pirpamer L, Hofer E, Voortman MM, Barro C, Leppert D, Benkert P, Ropele S, Enzinger C, Fazekas F, et al. Serum neurofilament light levels in normal aging and their association with morphologic brain changes. Nat Commun. 2020;11(1):1-9.

92. Abdelhak A, Huss A, Kassubek J, Tumani H, Otto M. Serum GFAP as a biomarker for disease severity in multiple sclerosis. Sci Rep. 2018;8(1):1-7.

93. Chiu M-J, Fan L-Y, Chen T-F, Chen Y-F, Chieh J-J, Horng H-E. Plasma tau levels in cognitively normal middle-aged and older adults. Front Aging Neurosci. 2017;9:51.

94. Gardner RC, Rubenstein R, Wang KK, Korley FK, Yue JK, Yuh EL, Mukherje P, Valadka AB, Okonkwo DO, Diaz-Arrastia R, et al. Age-related differences in diagnostic accuracy of plasma glial fibrillary acidic protein and tau for identifying acute intracranial trauma on computed tomography: a track-TBI study. J Neurotrauma. 2018;35(20):2341-50

95. Ward MD, Weber A, Merrill VD, Welch RD, Bazarian JJ, Christenson RH. Predictive performance of traumatic brain injury biomarkers in high-risk elderly patients. J Appl Lab Med. 2020;5(1):91-100.

96. Iverson GL, Reddi PJ, Posti JP, Kotilainen A-K, Tenovuo O, Öhman J, Zetterberg H, Blennow K, Luoto TM. Serum neurofilament light is elevated differentially in older adults with uncomplicated mild traumatic brain injuries. J Neurotrauma. 2019;36(16):2400-6.

97. Calcagnile O, Holmén A, Chew M, Undén J. S100B levels are affected by older age but not by alcohol intoxication following mild traumatic brain injury. Scand J Trauma Emerg Med. 2013;21(1):1-6.

98. Shahim P, Politis A, van der Merwe A, Moore B, Ekanayake V, Lippa SM, Chou Y-Y, Pham DL, Butman JA, Diaz-Arrastia R, et al. Time course and diagnostic utility of $\mathrm{nfl}$, tau, GFAP, and uch-L1 in subacute and chronic TBI. Neurology. 2020;95(6):623-36.

99. Shahim P, Tegner Y, Gustafsson B, Gren M, Ärlig J, Olsson M, Lehto N, Engström $\AA$, Höglund K, Portelius E, et al. Neurochemical aftermath of repetitive mild traumatic brain injury. JAMA Neurol. 2016;73(11):1308-15.

100. Pattinson CL, Shahim P, Taylor P, Dunbar K, Guedes VA, Motamedi V, Lai C, Devoto C, Peyer J, Roy MJ, et al. Elevated tau in military personne relates to chronic symptoms following traumatic brain injury. J Head Trauma Rehabil. 2020;35(1):66-73.

101. Bogoslovsky T, Wilson D, Chen Y, Hanlon D, Gill J, Jeromin A, Song L, Moore C, Gong Y, Kenney K, et al. Increases of plasma levels of glial 
fibrillary acidic protein, tau, and amyloid $\beta$ up to 90 days after traumatic brain injury. J Neurotrauma. 2017;34(1):66-73.

102. Hamdeh SA, Shevchenko G, Mi J, Musunuri S, Bergquist J, Marklund N. Proteomic differences between focal and diffuse traumatic brain injury in human brain tissue. Sci Rep. 2018;8(1):1-15.

103. Lewis LM, Schloemann DT, Papa L, Fucetola RP, Bazarian J, Lindburg M, Welch RD. Utility of serum biomarkers in the diagnosis and stratification of mild traumatic brain injury. Acad Emerg Med. 2017;24(6):710-20.

104. Wallace $\mathrm{C}$, Zetterberg $\mathrm{H}$, Blennow $\mathrm{K}$, van Donkelaar $\mathrm{P}$. No change in plasma tau and serum neurofilament light concentrations in adolescent athletes following sport-related concussion. PloS ONE. 2018;13(10): 0206466.

105. Kawata K, Rubin LH, Takahagi M, Lee JH, Sim T, Szwanki V, Bellamy A, Tierney R, Langford D. Subconcussive impact-dependent increase in plasma s100 $\beta$ levels in collegiate football players. J Neurotrauma. 2017;34(14):2254-60.

106. Oliver JM, Jones MT, Anzalone AJ, Kirk KM, Gable DA, Repshas JT, Johnson TA, Höglund K, Blennow K, Zetterberg H. A season of american football is not associated with changes in plasma tau. J Neurotrauma. 2017;34(23):3295-300.

107. Voormolen DC, Haagsma JA, Polinder S, Maas AIR, Steyerberg EW, Vuleković P, Sewalt CA, Gravesteijn BY, Covic A, Andelic N, Plass AM, von Steinbuechel N. Post-Concussion Symptoms in Complicated vs. Uncomplicated Mild Traumatic Brain Injury Patients at Three and Six Months Post-Injury: Results from the CENTER-TBI Study. J Clin Med. 2019;8(11):1921. https://doi.org/10.3390/jcm8111921.

108. Czeiter E, Amrein $K$, Gravesteijn BY, Lecky F, Menon DK, Mondello S, Newcombe VF, Richter S, Steyerberg EW, Vyvere TV, et al. Blood biomarkers on admission in acute traumatic brain injury: relations to severity, ct findings and care path in the center-tbi study. EBioMedicine. 2020;56:102785.

109. Huebschmann NA, Luoto TM, Karr JE, Berghem K, Blennow K, Zetterberg H, Ashton NJ, Simrén J, Posti JP, Gill JM, et al. Comparing glial fibrillary acidic protein (GFAP) in serum and plasma following mild traumatic brain injury in older adults. Front Neurol. 2020;11:1054.

110. Allouchery G, Moustafa F, Roubin J, Pereira B, Schmidt J, Raconnat J, Pic D, Sapin V, Bouvier D. Clinical validation of S100B in the management of a mild traumatic brain injury: issues from an interventional cohort of 1449 adult patients. Clin Chem Lab Med. 2018;56(11):1897-904.

111. Jones CMC, Harmon C, McCann M, Gunyan H, Bazarian JJ. S100b outperforms clinical decision rules for the identification of intracranial injury on head ct scan after mild traumatic brain injury. Brain Inj. 2020;34(3):407-14.

112. Egea-Guerrero JJ, Rodríguez-Rodríguez A, Quintana-Díaz M, Freire-Aragón MD, Raya-Collados D, Hernández-García C, Ortiz-Manzano Á, Vilches-Arenas A, Díez-Naz A, Guerrero JM, et al. Validation of S100B use in a cohort of spanish patients with mild traumatic brain injury: a multicentre study. Brain Inj. 2018;32(4):459-63.

113. Diaz-Arrastia R, Wang KK, Papa L, Sorani MD, Yue JK, Puccio AM, McMahon PJ, Inoue T, Yuh EL, Lingsma HF, et al. Acute biomarkers of traumatic brain injury: relationship between plasma levels of ubiquitin c-terminal hydrolase-L1 and glial fibrillary acidic protein. J Neurotrauma. 2014;31(1):19-25.

114. Undén L, Calcagnile O, Undén J, Reinstrup P, Bazarian J. Validation of the Scandinavian guidelines for initial management of minimal, mild and moderate traumatic brain injury in adults. BMC Medicine. 2015;13(1):1-9.

115. Minkkinen $M$, Iverson $G L$, Kotilainen A-K, Pauniaho S-L, Mattila VM, Lehtimäki T, Berghem K, Posti JP, Luoto TM. Prospective Validation of the Scandinavian Guidelines for Initial Management of Minimal, Mild, and Moderate Head Injuries in Adults. J Neurotrauma. 2019;36(20):2904-12.

116. Calcagnile $\mathrm{O}$, Anell A, Undén J. The addition of S100B to guidelines for management of mild head injury is potentially cost saving. BMC Neurology. 2016;16(1):200.

117. Oris C, Pereira B, Durif J, Simon-Pimmel J, Castellani C, Manzano S, Sapin $\mathrm{V}$, Bouvier D. The biomarker S100B and mild traumatic brain injury: a meta-analysis. Pediatrics. 2018;141(6). https://doi.org/10.1542/ peds.2018-0037.

118. Ananthaharan A, Kravdal G, Straume-Naesheim TM. Utility and effectiveness of the Scandinavian guidelines to exclude computerized tomography scanning in mild traumatic brain injury-a prospective cohort study. BMC Emerg Med. 2018;18(1):44.
119. Food Administration D, et al. FDA authorizes marketing of first blood test to aid in the evaluation of concussion in adults. FDA News Release. 2018. p 2-4. https://www.fda.gov/news-events/press-announcements/fdaauthorizes-marketing-first-blood-test-aid-evaluation-concussionadults. Accessed 06 Sep 2021.

120. Schencker L. A rapid blood test for mild concussions? New Abbott test gains FDA clearance. Chicago Tribune. 2021. https://www. chicagotribune.com/business/ct-biz-abbott-blood-test-concussionsfda-approval-20210111-5qddey336fdnjeuiwopcioykty-story.html. Accessed 03 Sep 2021.

121. Okonkwo DO, Puffer RC, Puccio AM, Yuh EL, Yue JK, Diaz-Arrastia R, Korley FK, Wang KK, Sun X, Taylor SR, et al. Point-of-care platform blood biomarker testing of glial fibrillary acidic protein versus $s 100$ calcium-binding protein b for prediction of traumatic brain injuries: A transforming research and clinical knowledge in traumatic brain injury study. J Neurotrauma. 2020;37(23):2460-7.

122. Metting Z, Wilczak N, Rodiger L, Schaaf J, Van Der Naalt J. GFAP and $\mathrm{S} 100 \mathrm{~B}$ in the acute phase of mild traumatic brain injury. Neurology. 2012;78(18):1428-33.

123. Silverberg ND, Gardner AJ, Brubacher JR, Panenka WJ, Li JJ, Iverson GL. Systematic review of multivariable prognostic models for mild traumatic brain injury. J Neurotrauma. 2015;32(8):517-26. https://doi.org/10.1089/ neu.2014.3600.

124. Pattinson CL, Meier TB, Guedes VA, Lai C, Devoto C, Haight T, Broglio SP, McAllister T, Giza C, Huber D, et al. Plasma biomarker concentrations associated with return to sport following sport-related concussion in collegiate athletes - a concussion assessment, research, and education (CARE) consortium study. JAMA Netw Open. 2020;3(8):2013191.

125. Babcock L, Byczkowski T, Wade SL, Ho M, Bazarian JJ. Inability of S100B to predict post-concussion syndrome in children who present to the emergency department with mild traumatic brain injury: a brief report. Pediatr Emerg Care. 2013;29(4):458.

126. Hossain I, Mohammadian M, Takala RS, Tenovuo O, Azurmendi Gil L, Frantzén J, Van Gils M, Hutchinson PJ, Katila AJ, Maanpää H-R, et al. Admission levels of total tau and $\beta$-amyloid isoforms $1-40$ and $1-42$ in predicting the outcome of mild traumatic brain injury. Front Neurol. 2020;11:325.

127. Ma M, Lindsell CJ, Rosenberry CM, Shaw GJ, Zemlan FP. Serum cleaved tau does not predict postconcussion syndrome after mild traumatic brain injury. Am J Emerg Med. 2008;26(7):763-8.

128. Atif $\mathrm{H}$, Hicks SD. A review of microrna biomarkers in traumatic brain injury. J Exp Neurosci. 2019;13:1179069519832286.

129. Huebschmann NA, Luoto TM, Karr JE, Berghem K, Blennow K, Zetterberg H, Ashton NJ, Simrén J, Posti JP, Gill JM, et al. Comparing glial fibrillary acidic protein (gfap) in serum and plasma following mild traumatic brain injury in older adults. Front Neurol. 2020;11:1054.

130. Janigro D, Kawata K, Silverman E, Marchi N, Diaz-Arrastia R. Is salivary s100b a biomarker of traumatic brain injury? a pilot study. Front Neurol. 2020;11:528.

131. Olczak M, Poniatowski ŁA, Niderla-Bielińska J, Kwiatkowska M, Chutorański D, Tarka S, Wierzba-Bobrowicz T. Concentration of microtubule associated protein tau (mapt) in urine and saliva as a potential biomarker of traumatic brain injury in relationship with blood-brain barrier disruption in postmortem examination. Forensic Sci Int. 2019;301:28-36.

132. Johnson VE, Weber MT, Xiao R, Cullen DK, Meaney DF, Stewart W, Smith $\mathrm{DH}$. Mechanical disruption of the blood-brain barrier following experimental concussion. Acta Neuropathol. 2018;135(5):711-26.

133. Weissberg I, Veksler R, Kamintsky L, Saar-Ashkenazy R, Milikovsky DZ, Shelef I, Friedman A. Imaging blood-brain barrier dysfunction in football players. JAMA Neurol. 2014;71(11):1453-5.

134. Lindblad C, Nelson DW, Zeiler FA, Ercole A, Ghatan PH, von Horn H, Risling M, Svensson M, Agoston DV, Bellander B-M, et al. Influence of blood-brain barrier integrity on brain protein biomarker clearance in severe traumatic brain injury: A longitudinal prospective study. J Neurotrauma. 2020;37(12):1381-91.

135. Csuka E, Morganti-Kossmann MC, Lenzlinger PM, Joller H, Trentz O, Kossmann T. IL-10 levels in cerebrospinal fluid and serum of patients with severe traumatic brain injury: relationship to IL-6, TNF- $\alpha$, TGF- $\beta 1$ and blood-brain barrier function. J Neuroimmunol. 1999;101(2):211-21. 
136. Başkaya MK, Rao AM, Doğan A, Donaldson D, Dempsey RJ. The biphasic opening of the blood-brain barrier in the cortex and hippocampus after traumatic brain injury in rats. Neurosci Lett. 1997;226(1):33-6.

137. Wood $\mathrm{H}$. Evidence of blood-brain barrier disruption after concussion. Nat Rev Neurol. 2018;14(5):254.

138. Habgood M, Bye N, Dziegielewska K, Ek C, Lane M, Potter A, Morganti-Kossmann C, Saunders N. Changes in blood-brain barrier permeability to large and small molecules following traumatic brain injury in mice. Eur J Neurosci. 2007;25(1):231-8.

139. Readnower RD, Chavko M, Adeeb S, Conroy MD, Pauly JR, McCarron RM, Sullivan PG. Increase in blood-brain barrier permeability, oxidative stress, and activated microglia in a rat model of blast-induced traumatic brain injury. J Neurosci Res. 2010;88(16):3530-9.

140. Kerr ZY, Zuckerman SL, Wasserman EB, Covassin T, Djoko A, Dompier TP. Concussion symptoms and return to play time in youth, high school, and college american football athletes. JAMA Pediatrics. 2016;170(7): 647-53.

\section{Publisher's Note}

Springer Nature remains neutral with regard to jurisdictional claims in published maps and institutional affiliations.

Ready to submit your research? Choose BMC and benefit from:

- fast, convenient online submission

- thorough peer review by experienced researchers in your field

- rapid publication on acceptance

- support for research data, including large and complex data types

- gold Open Access which fosters wider collaboration and increased citations

- maximum visibility for your research: over $100 \mathrm{M}$ website views per year

At BMC, research is always in progress.

Learn more biomedcentral.com/submissions 